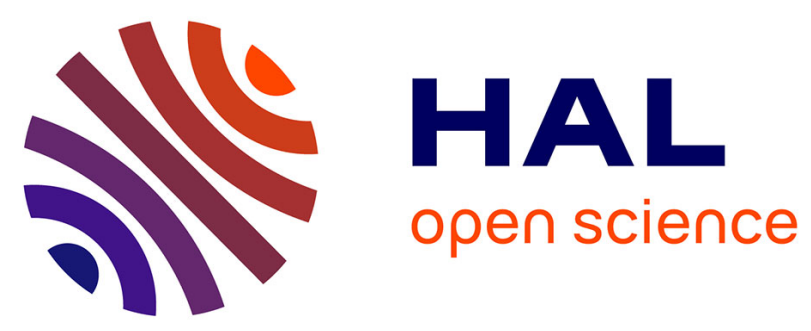

\title{
Advanced in Vitro Experimental Models for Tissue Engineering-based Reconstruction of a 3D Dentin/pulp Complex: a Literature Review
}

Hadjichristou Christina1, Imad About, Koidis Petros3, Bakopoulou Athina4

\section{- To cite this version:}

Hadjichristou Christina1, Imad About, Koidis Petros3, Bakopoulou Athina4. Advanced in Vitro Experimental Models for Tissue Engineering-based Reconstruction of a 3D Dentin/pulp Complex: a Literature Review. Stem Cell Reviews and Reports, In press, 10.1007/s12015-020-10069-8 . hal03191588

\author{
HAL Id: hal-03191588 \\ https://hal.science/hal-03191588
}

Submitted on 7 Apr 2021

HAL is a multi-disciplinary open access archive for the deposit and dissemination of scientific research documents, whether they are published or not. The documents may come from teaching and research institutions in France or abroad, or from public or private research centers.
L'archive ouverte pluridisciplinaire HAL, est destinée au dépôt et à la diffusion de documents scientifiques de niveau recherche, publiés ou non, émanant des établissements d'enseignement et de recherche français ou étrangers, des laboratoires publics ou privés. 
Title: Advanced in vitro experimental models for tissue engineering-based reconstruction of a 3D dentin/pulp complex: a literature review.

Hadjichristou Christina1, About Imad2, Koidis Petros3, Bakopoulou Athina4

1 Department of Prosthodontics, School of Dentistry, Faculty of Health Sciences, Aristotle University of Thessaloniki (A.U.Th), GR-54124 Thessaloniki, Greece. Electronic address: cchatzic@ dent.auth.gr

2 Aix Marseille University, Centre National de la Recherche Scientifique, Institute of Movement Sciences, Marseille, France. Electronic address: imad.about@univ-amu.fr

3 Department of Prosthodontics, School of Dentistry, Faculty of Health Sciences, Aristotle University of Thessaloniki (A.U.Th), GR-54124 Thessaloniki, Greece. Electronic address: pkoidis@ dent.auth.gr 4 Department of Prosthodontics, School of Dentistry, Faculty of Health Sciences, Aristotle University of Thessaloniki (A.U.Th), GR-54124 Thessaloniki, Greece. Electronic address: abakopoulou@ dent.auth.gr. 


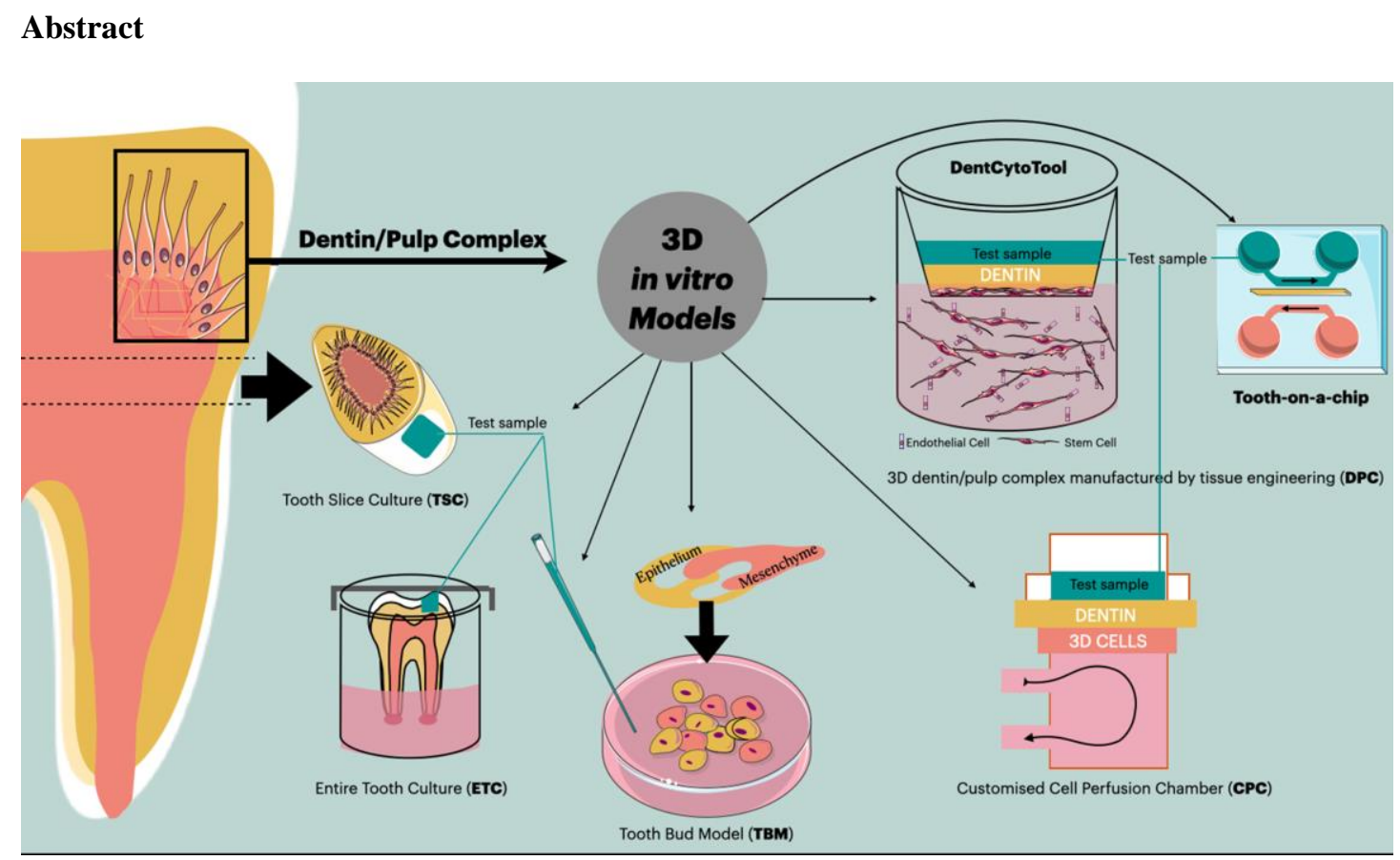

Objective: Experimental procedures have been used to monitor cellular responses at the dentin/pulp interface. Aiming to divert from in vivo studies and oversimplified two-dimensional assays, three-dimensional (3D) models have been developed. This review provides an overview of existing literature, regarding 3D in vitro dentin/pulp reconstruction.

Material \& Methods: PubMed, Scopus, Cochrane Library and Web of Science- were systematically searched for attributes between 1998-2020. The search focused on articles on the development of three-dimensional tools for the reconstruction of a dentin/pulp complex under in vitro conditions, which were then screened and qualitatively assessed. Article grouping according to mode of implementation, resulted in five categories: the customised cell perfusion chamber $(\mathbf{C P C})(n=8)$, the tooth bud model $(\mathbf{T B M})(n=3)$, the $3 \mathrm{D}$ dentin/pulp complex manufactured by tissue engineering (DPC) $(n=6)$, the entire tooth culture (ETC) $(n=4)$ and the tooth slice culture model (TSC) $(n=5)$.

Results: A total of 26 publications, applying nine and eight substances for pulp and dentin representation respectively, were included. Natural materials and dentin components were the most widely utilized. The most diverse category was the DPC, while the CPC group was the test with the highest longevity. The most consistent categories were the ETC and TSC models, while the TBM presented as the most complete de novo approach. 
Conclusion: All studies presented with experimental protocols with potential upgrades. Solving the limitations of each category will provide a complete in vitro testing and monitoring tool of dental responses to exogenous inputs.

Clinical Relevance: The 3D dentin/pulp complexes are valid supplementary tools for in vivo studies and clinical testing.

Keywords: dentin pulp complex, three-dimensional, tissue engineering, tissue manufacturing, regeneration, bioengineering.

\section{Introduction}

Dentin and the dental pulp are two components of the dental tissue, which function as a complex. Odontoblasts, lining the circumference of the pulp, give rise to predentin and eventually to dentin and in turn dentin -being more robust- protects the dental pulp [1]. Stimuli from the external environment are transferred from dentin to the pulp and in return the pulp responds accordingly [2]. This sensitive system, which is a structure lying within the dental cavity, is constantly exposed to acids, sugars and thermal shocks [3]. The scientific community has been occupied with experimental setups in order to recapitulate cellular mechanisms underlying certain functions or to monitor reactions to external stimuli and materials[4]. These efforts were addressed to solely pulp components, neglecting the synergistic effect of dentin and probably altering the output. With this in mind, investigations were directed in 2-dimensional experiments incorporating slices of dentin [5-8]. However, this was also troublesome, as it did not recapitulate the complexity or the structural anatomy of the natural 3D tissue. The factor of dimensionality is also degraded as cells are organized in complex three dimensional (3D) extracellular matrices (ECM) interacting with surrounding cells [9]. For these reasons, researchers have focused on developing 3D matrices to host cells, in a way that better mimics their physical environment. Threedimensional analogues of the dentin/pulp complex include the customised cell perfusion chamber test with particular reference to the artificial pulp chamber and cell seeding in 3D polyamide meshes, instead of the initial 2D cell cultures on coverslips [10-13].

Another example is "the entire tooth culture" presented in 2005, in which extracted teeth with undeveloped roots were suspended in polystyrene well plates using metal wires to keep the roots in culture medium [14]. The 
ability of these teeth to behave similarly to the clinical situation when placed in culture, (i.e. the ability of the cells to proliferate and migrate to injury sites after pulp exposure) was evaluated [14-17]. Another example is the tooth bud model illustrating organ germs representing a revival of the natal structure of the human tooth [18-20]. This attempt has been brought to life by culturing distinct mesenchymal and epithelial cell populations as representatives of pulp and dentin, respectively, in the form of de novo synthesis based on the embryological derivative of the complex tooth tissue.

More recently, a new advancement has been proposed in the medical field, the microfluidic devices, lined with living human cells. These small devices -microchips- that fit between the two fingers are constructed by PDMS and they replicate the microarchitecture and basic functions of human organs such as kidney [21], blood-brain barrier [22], lung [23], liver [24]. Dentistry followed this trend and devised the "tooth on a chip" [25]. This model would serve as a biocompatibility assessment tool by combining a pulp and a cavity chamber in two compartments separated by a dentin fragment. Other examples utilising 3D tissue engineering for this purpose are met through stiffness modulation, bioprinting, hanging culture inserts, and will be discussed later in detail.

For the scope of this review, studies on the in vitro 3D dentin/pulp complex reconstruction were identified and analysed regarding the recapitulation of the pulp component, the dentin component, the modes of the assembly of the two components, the interventions and intentions of use of these devices, as well as the biological endpoints and the actual efficacy of each method.

There is still much to learn from the in vitro testing, although it is accepted that this will not totally replace the in vivo and clinical tests prior to material market release. There are several reasons that enforce seeking alternatives to in vivo animal models and clinical trials. These are the limited number of test subjects as well as the limited availability of donor tissue, the high cost of purchase and maintenance as well as the ethical concerns of pain and discomfort to living subjects. Adding to this notion, the predictive value of animal models and the projection of the results to humans and donor specific factors -such as disease or genetics- may still influence the outcome [26]. As in other medical fields -such as cancer research- a bridging vehicle is sought, halfway between unrealistic and oversimplified 2D in vitro models and animal models[27]. Nonetheless, in vitro methods should be used for initial screening purposes offering high throughput information, aiding in the apprehension of cellular mechanism responses through an in vitro environment that closely mimics the natural tissue. The aim of this review is to reveal and analyze the studies and experimental setups which have been 
implemented with a 3D in vitro rational with the ultimate purpose to mimic the dentin/pulp complex as closely as possible and therefore to be used as monitoring tools for the biological processes and reactions of this complex tissue to external stimuli.

\section{Material \& Methods}

Study Design

All authors involved in this study developed a protocol for a qualitative review of the literature based on recommended methods. The main research question of this study was: Do in vitro 3D studies, regenerating the dentin/pulp complex, resemble the native tissue successfully? The review followed the PRISMA (Preferred Reporting Items for Systematic Reviews and Meta-Analyses)-statement.

Inclusion and exclusion criteria

Literature research was performed by applying specific search terms, aiming to find publications with the purpose to device a 3D analogue of the dentin/pulp complex. Eligibility criteria included journal articles published until February 2020 in peer-reviewed journals regarding in vitro studies. The attributes which did not provide information for both the pulp and the dentin component as well as their assembly method were eliminated. Case reports, finite element analysis studies, review articles, and in vivo studies were also excluded.

\section{Search strategy}

Four scientific databases - Pubmed, Scopus and Cochrane Library and Web of Science- were used for the search. The key words for this search were: "(dentin pulp complex OR pulp dentine OR tooth) AND (3D OR three dimensional) AND (tissue engineering OR tissue manufacturing OR regeneration OR bioengineering)". The search was limited to articles written in English, published until February 2020. Additional articles from paper references were added manually.

Study selection

After removing duplicates, the full content of the resulting papers was screened manually. Inclusion and exclusion criteria were applied for the final selection. The included studies were subdivided into studies performing customised cell perfusion chamber tests, tooth bud models, 3D dentin/pulp complex manufactured by tissue engineering studies, the entire tooth culture models and the tooth slice organ culture models. 


\section{Data extraction}

Two independent reviewers assessed the titles and abstracts of the collected studies and data were extracted from the full texts of the finally included studies. The data collected were: author(s) and year of study, method for pulp representation, method for dentin regeneration, assembly manner for dentin/pulp complex, intervention - aim(s), methods, biological end-points, and efficacy measurement (outcomes or main findings). Disagreements during study selection, data extraction, and quality assessment were resolved by discussion between the two reviewers.

Risk of bias and quality assessment

Studies were not evaluated for risk of bias as there is no published risk - of - bias approach for mechanistic studies or framework for rating confidence in bodies of evidence for in vitro studies.

\section{Results}

Search results and study characteristics

The initial search procedure using PubMed $(n=812)$, Web of Science $(n=385)$, Scopus $(n=40)$, and Cochrane $(n=41)$. Another six records were added through other sources, leading to an overall of 1284 search results. After screening titles and abstracts, the total findings remaining were 88. The excluded studies involved evaluation of tissues other than dentin/pulp complex $(n=154)$, review articles $(n=51)$, in vivo $(n=64)$ or clinical testing $(n=54)$, case reports $(n=31)$ not written in English $(n=82)$ or irrelevant to the subject $(n=763)$. Out of the 88 articles remaining, 42 were duplicates, and as a result, the total findings were reduced to 46 unique journal articles. Following the inclusion and exclusion criteria, 20 studies had to be excluded leading to a total of 26 , which were further probed and later synthesized in this review (Figure 1).

The retrieved studies were first found in 1998. In the past 22 years, the interest in the subject has been steady as the timeline reveals, on average 4 publications per 5 years, until 2018. In the last two years, 2019-2020, 6 relevant studies have already been published, indicating an increase in the interest towards this subject. 


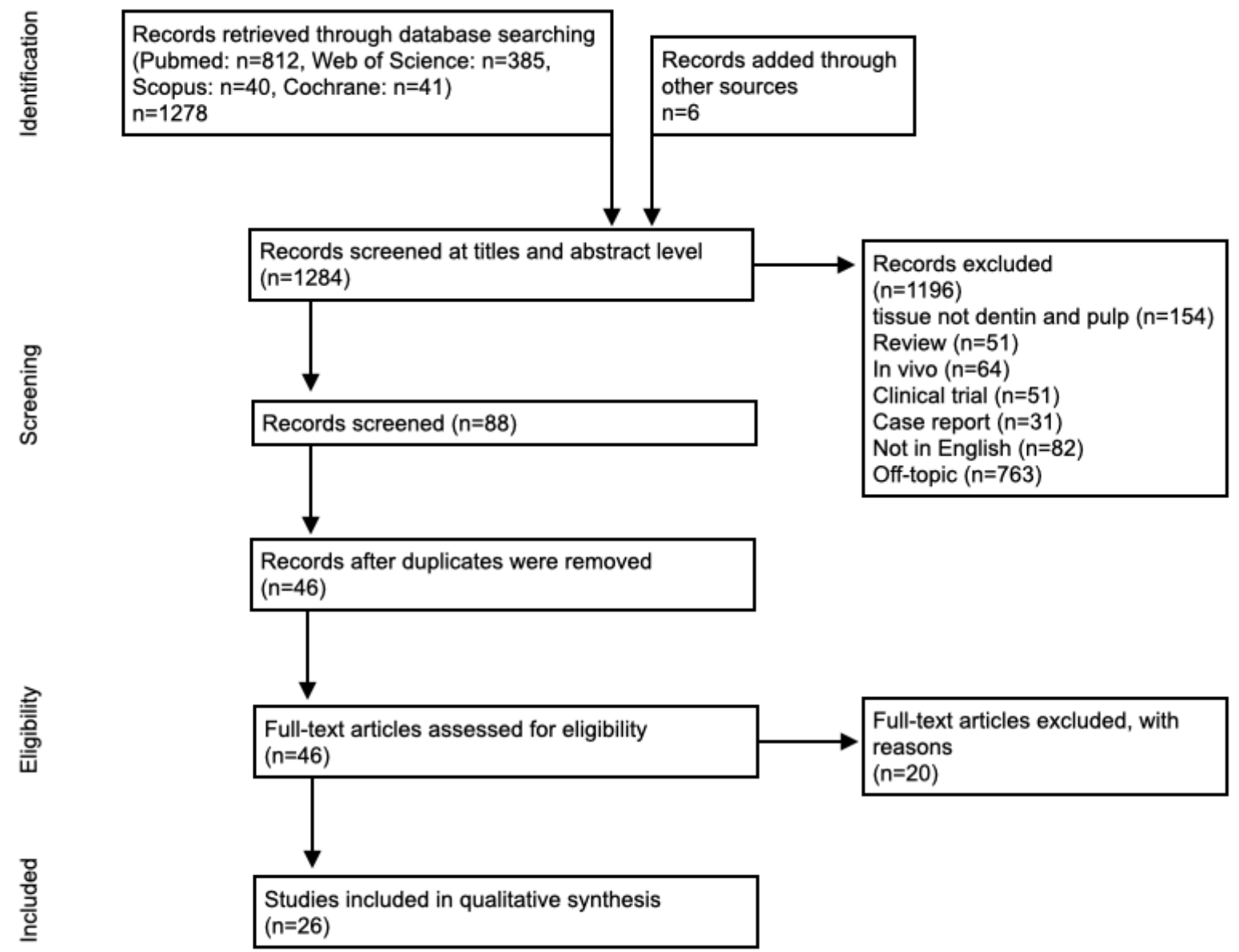

Figure 1: Flow diagram of the review process according to "Preferred Reporting items for systematic reviews and meta-Analyses: The Prisma Statement" [28]

\section{Types of Three-dimensional dentin/pulp complexes}

All of the 26 included studies were assigned to subgroups according to their defined category: customised cell perfusion chamber $(n=8)$, tooth bud model $(n=3), 3 D$ dentin/pulp complex manufactured by tissue engineering $(n=6)$, entire tooth culture $(n=4)$ and the tooth slice organ culture model $(n=5)$.

In total, nine materials were used as a $3 \mathrm{D}$ substrate for the representation of the dental pulp, with polyamide meshes and the natural pulp being the most frequently utilized. Other natural materials were gelatin, collagen, fibrinogen, and their combinations. Synthetic materials consisted of nylon, polyamide, polystyrene meshes and GelMa.

The dentin analogue was mostly represented by natural dentin discs, dentin fragments or cavities in dentin, of either human or bovine origin. Others employed the same gels used for manufacturing the pulp, but at higher 
concentrations (e.g. higher stiffnesses of GelMa or Gelatin). A few studies used cell sheet layers of appropriate cell lines or single-cell suspensions in a 3D arrangement (Table 1). The most popular assembly method for the development of dentin/pulp complex was through a customized cell perfusion chamber. Other methods were 3D printing of the two tissues, hanging culture inserts, compartmentalized PDMS molds and direct cell sheet layering. In the case of the entire tooth culture and the tooth slice organ culture, the two tissues (dentin and the dental pulp) were naturally in contact beforehand.

\begin{tabular}{|l|l|l|l|}
\hline Pulp analogue material & $\begin{array}{l}\text { Number of studies } \\
\text { (reference) }\end{array}$ & Dentin analogue materials & Number of studies \\
(reference)
\end{tabular}

Table 1: Overview of the materials used for manufacturing the three-dimensional dentin/pulp complexes.

\section{Customised Cell perfusion chamber.}

The included studies in this sector used customized cell perfusion chambers. Animal-derived cells were seeded in three-dimensional scaffolds, such as nylon meshes [10], polyamide meshes [11,12,29,40,41] or polystyrene [38]. In all studies, cells were bovine-derived fibroblasts except from Jiang et al. who used mouse fibroblasts. All studies used dentin discs as dentin analogues to separate the pulp compartment from the exposed dentin side, and the most commonly found dentin thickness was $500 \mu \mathrm{m}[10,11,39,40]$. Two studies tested variations of dentin thicknesses ranging from 100-1000 $\mu \mathrm{m}$ [12,38]. All dentin discs followed a similar protocol for smear removal (50\% citric acid for 30') and sterilization by autoclave (121C/25') except from Jiang et al., who used $70 \%$ ethanol for disinfection purposes. All experimental designs consisted of dynamic cultures, as perfusion was 
incorporated in the setup, within the limit of $0.3-5 \mathrm{ml} / \mathrm{h}$. Lower flow values $(0.3 \mathrm{ml} / \mathrm{h})$ were used for the first $24 \mathrm{~h}$ of culture. The perfusion was then arrested during the incorporation of the test specimens and the perfusion was re-initiated for another $24 \mathrm{~h}$ period at higher flow values. The aim of these studies was to test the cytocompatibility of dental materials via MTT assay, 24h post-exposure to: dental adhesives, resin cements, primers, resin-modified glass ionomer cements, zinc oxide eugenol, zinc phosphate cements. Outcomes of these studies indicated the importance of incorporating the dentin barrier. Indeed, the lower dentin thicknesses were insufficient in terms of protecting the cells against cytotoxic effects by various bonding agents [12,38]. The parameter of perfusion, also simulating the natural condition in the natural tooth, gave controversial results. This parameter was material-dependent as some studies revealed an increase in the cytotoxicity caused by glass ionomer cements (Vitrebond, Ketac-Fil) by increasing the perfusion rate from 0.2 to 3 or $5 \mathrm{ml} / \mathrm{h}[10,48]$. Conversely, high perfusion rates $(2 \mathrm{ml} / \mathrm{h})$ caused a decrease in cytotoxicity caused by a bonding agent, Syntac, where the authors noted that this open-test system may have simulated the natural tooth more closely as these materials have not been found to exert adverse reactions in vivo where the material is being washed away by the bloodstream [41]. Among different bonding agents, Sengun et al. reported that the contents of each material had different cytotoxic effects. However, they were introduced in identical conditions in the cell perfusion chambers, stating that bis-GMA and UDMA containing bonding agents were more cytotoxic than those containing TEGDMA and HEMA [39]. Recently, Jiang et al. mentioned that the type of adhesive, whether totaletch or self-etch, also had an effect, with the former being more cytotoxic than the latter [38]. These parameters: dentin thickness, perfusion, the material under investigation, reinforced the importance of employing a threedimensional system to mimic the natural situation better.

\begin{tabular}{|c|c|c|c|c|c|c|}
\hline $\begin{array}{l}\text { Author, } \\
\text { year }\end{array}$ & $\begin{array}{l}\text { Pulp analogue } \\
\text { (Scaffold/cells) }\end{array}$ & $\begin{array}{l}\text { Dentin } \\
\text { analogue }\end{array}$ & Assembly & Intervention & $\begin{array}{l}\text { Methods/ } \\
\text { Biological } \\
\text { endpoints }\end{array}$ & $\begin{array}{l}\text { Efficacy } \\
\text { measurement / } \\
\text { outcomes }\end{array}$ \\
\hline $\begin{array}{l}\text { Schmalz } \\
1999\end{array}$ & $\begin{array}{l}\text { nylon mesh/ } \\
\text { fibroblasts }\end{array}$ & $\begin{array}{l}\text { Dentin discs } \\
-(500 \mu \mathrm{m})- \\
\text { bovine } \\
\text { incisors. } \\
\text {-treatment: } \\
\text { etching } 50 \%\end{array}$ & $\begin{array}{l}\text { Customised } \\
\text { Cell } \\
\text { perfusion } \\
\text { chamber }\end{array}$ & $\begin{array}{l}\text { Insertion of } \\
\text { dental filling } \\
\text { materials } \\
\text { (cements): } \\
\text { Zinc } \\
\text { phosphate }\end{array}$ & $\begin{array}{l}\text { MTT assay } \\
24 \mathrm{~h} \text { after } \\
\text { exposure to } \\
\text { sample } \\
\pm \text { perfusion }\end{array}$ & $\begin{array}{l}\text { Vitrebond was } \\
\text { cytotoxic w/o } \\
\text { perfusion. }\end{array}$ \\
\hline
\end{tabular}




\begin{tabular}{|c|c|c|c|c|c|c|}
\hline & & $\begin{array}{l}\text { citric } 30^{\prime} \\
\text { for smear } \\
\text { removal, } \\
\text { autoclaved } \\
\left(121^{\circ} \mathrm{C}, \quad 25\right. \\
\min )\end{array}$ & & $\begin{array}{l}\text { (Harvard) } \\
\text { Zinc oxide- } \\
\text { eugenol } \\
\text { cement } \\
\text { Glass ionomer } \\
\text { cement } \\
\text { (Ketac-fil) } \\
\text { Resin } \\
\text { modified glass } \\
\text { ionomer } \\
\text { cement } \\
\text { (Vitrebond) }\end{array}$ & $\begin{array}{l}(0.3 \text { or } 5 \\
\mathrm{ml} / \mathrm{h})\end{array}$ & $\begin{array}{l}\text { significant } \\
\text { difference from } \\
\text { w/o perfusion. } \\
0.3 \rightarrow 5 \quad \mathrm{ml} / \mathrm{h} \\
\text { significant } \\
\text { difference } \\
\text { (except ketac } \\
\text { silver) but still } \\
\text { not cytotoxic. }\end{array}$ \\
\hline $\begin{array}{l}\text { Schuster } \\
2001\end{array}$ & $\begin{array}{l}\text { Polyamide } \\
\text { meshes/bovine } \\
\text { pulp-derived } \\
\text { cells }\end{array}$ & $\begin{array}{l}\text { Dentin discs } \\
-(500 \mu \mathrm{m})- \\
\text { bovine } \\
\text { incisors. } \\
\text {-treatment: } \\
\text { etching } 50 \% \\
\text { citric } 30 \text { ", } \\
\text { for smear } \\
\text { removal, } \\
\text { autoclaved } \\
\left(121^{\circ} \mathrm{C}, \quad 25\right. \\
\text { min) }\end{array}$ & $\begin{array}{l}\text { Customised } \\
\text { Cell } \\
\text { perfusion } \\
\text { chamber }\end{array}$ & $\begin{array}{l}\text { Insertion of } \\
\text { dental filling } \\
\text { materials } \\
\text { (cements): } \\
\text { Zinc } \\
\text { phosphate } \\
\text { cement } \\
\text { (Harvard) } \\
\text { Zinc oxide- } \\
\text { eugenol } \\
\text { cement } \\
\text { Glass ionomer }\end{array}$ & $\begin{array}{l}\text { MTT assay } \\
24 \mathrm{~h} \text { after } \\
\text { exposure to } \\
\text { sample } \\
\pm \text { perfusion } \\
(0.3 \text { or } 2 \\
\mathrm{ml} / \mathrm{h})\end{array}$ & $\begin{array}{l}\text { lower survival } \\
\text { rates } \\
\text { perfusion } \\
\text { conditions, } \\
\text { compared with } \\
\text { static } \\
\text { experiments. } \\
\text { However, not } \\
\text { statistically } \\
\text { significant. } \\
\text { Only Vitrebond } \\
\text { was cytotoxic }\end{array}$ \\
\hline
\end{tabular}




\begin{tabular}{|c|c|c|c|c|c|c|}
\hline & & & & $\begin{array}{l}\text { cement } \\
\text { (Ketac-fil, } \\
\text { ketac-silver) } \\
\text { Resin } \\
\text { modified glass } \\
\text { ionomer } \\
\text { cement light } \\
\text { cured } \\
\text { (Vitrebond) }\end{array}$ & & \\
\hline $\begin{array}{l}\text { Schmalz } \\
2002\end{array}$ & $\begin{array}{l}\text { Polyamide } \\
\text { meshes/bovine } \\
\text { pulp-derived } \\
\text { cells }\end{array}$ & $\begin{array}{l}\text { Dentin discs } \\
-(500 \mu \mathrm{m}) \text { - } \\
\text { bovine } \\
\text { incisors. } \\
\text {-treatment: } \\
\text { etching } 50 \% \\
\text { citric } \quad 30 \text { \% } \\
\text { for smear } \\
\text { removal, } \\
\text { autoclaved } \\
\left(121^{\circ} \mathrm{C}, \quad 25\right. \\
\text { min) }\end{array}$ & $\begin{array}{l}\text { Customised } \\
\text { Cell } \\
\text { perfusion } \\
\text { chamber }\end{array}$ & $\begin{array}{l}\text { Insertion of } \\
\text { dental } \\
\text { materials: All- } \\
\text { Bond 2, Prime } \\
\text { \& Bond NT, } \\
\text { Syntac SC, } \\
\text { Syntac } \\
\text { Classic, and } \\
\text { Prompt L-Pop }\end{array}$ & $\begin{array}{l}\text { MTT assay } \\
24 \mathrm{~h} \text { after } \\
\text { exposure to } \\
\text { sample } \\
\pm \text { perfusion } \\
(0.3 \text { or } 2 \\
\mathrm{ml} / \mathrm{h})\end{array}$ & $\begin{array}{l}\text { Only Syntac } \\
\text { Classic } \\
\text { significantly } \\
\text { decreased } \\
\text { the cell } \\
\text { activities. } \\
\text { 0.3ml/h } \\
\text { perfusion } \\
\text { increased } \\
\text { cytotoxicity, but } \\
2 \text { ml/h perfusion } \\
\text { reduced the } \\
\text { cytotoxicity } \\
\text { no effect when } \\
\text { with a } \\
\text { bonding agents } \\
\text { have }\end{array}$ \\
\hline
\end{tabular}




\begin{tabular}{|c|c|c|c|c|c|c|}
\hline & & & & & & $\begin{array}{l}0.5-\mathrm{mm} \text { dentin } \\
\text { barrier }\end{array}$ \\
\hline $\begin{array}{l}\text { Galler } \\
2005\end{array}$ & $\begin{array}{l}\text { Polyamide } \\
\text { meshes/calf- } \\
\text { bovine dental } \\
\text { papilla derived } \\
\text { cells }\end{array}$ & $\begin{array}{l}\text { Dentin discs } \\
-(100, \quad 200, \\
300 \text {, and } 500 \\
\mu \mathrm{m}) \\
\text {-bovine } \\
\text { incisors. } \\
\text {-treatment: } \\
\text { etching } 50 \% \\
\text { citric } \quad 30 \text { ", } \\
\text { for smear } \\
\text { removal, } \\
\text { autoclaved } \\
\left(121^{\circ} \mathrm{C}, \quad 25\right. \\
\text { min) }\end{array}$ & $\begin{array}{l}\text { Customised } \\
\text { Cell } \\
\text { perfusion } \\
\text { chamber }\end{array}$ & $\begin{array}{l}\text { Insertion of } \\
\text { dentin } \\
\text { contacting } \\
\text { materials: } \\
\text { Syntac Classic } \\
\text { (Primer), } \\
\text { Prompt L-Pop } \\
\text { (adhesive), } \\
\text { Vitrebond } \\
\text { (Resin } \\
\text { modified glass } \\
\text { ionomer } \\
\text { cement) }\end{array}$ & $\begin{array}{l}\text { MTT assay } \\
24 \mathrm{~h} \text { after } \\
\text { exposure to } \\
\text { sample, } \\
\pm \text { perfusion } \\
0.3-2 \mathrm{ml} / \mathrm{h}\end{array}$ & $\begin{array}{l}\text { Cell survival } \\
\text { rates for Syntac } \\
\text { Classic were } \\
\text { significantly } \\
\text { lower under } \\
\text { perfusion } \\
\text { conditions, no } \\
\text { sign diff } \\
\text { regarding dentin } \\
\text { thickness. } \\
\text { Vitrebond and } \\
\text { Prompt L-Pop } \\
\text { no statistical } \\
\text { difference } \\
\text { between static } \\
\text { and perfusion } \\
\text { conditions or } \\
\text { different dentin } \\
\text { thicknesses. } \\
\text { Vitrebond> L- } \\
\text { Syntac> } \\
\text { Poptotoxicity } \\
\text { and }\end{array}$ \\
\hline $\begin{array}{l}\text { Ulker } \\
2009\end{array}$ & $\begin{array}{l}\text { Polyamide } \\
\text { meshes/calf- } \\
\text { bovine dental }\end{array}$ & $\begin{array}{l}\text { Dentin discs } \\
-(500 \mu \mathrm{m})- \\
\text { bovine }\end{array}$ & $\begin{array}{l}\text { Customised } \\
\text { Cell } \\
\text { perfusion }\end{array}$ & $\begin{array}{l}\text { Insertion of } \\
\text { composite } \\
\text { resin cements: }\end{array}$ & $\begin{array}{l}\text { MTT assay } \\
24 \mathrm{~h} \text { after } \\
\text { exposure to }\end{array}$ & $\begin{array}{l}\text { Maxcem was } \\
\text { similar to the } \\
\text { negative control }\end{array}$ \\
\hline
\end{tabular}




\begin{tabular}{|c|c|c|c|c|c|c|}
\hline & $\begin{array}{l}\text { papilla-derived } \\
\text { cells }\end{array}$ & $\begin{array}{l}\text { incisors. } \\
\text {-treatment: } \\
\text { etching } 50 \% \\
\text { citric } 30 \text {, } \\
\text { for smear } \\
\text { removal, } \\
\text { autoclaved } \\
\left(121^{\circ} \mathrm{C}, \quad 25\right. \\
\min )\end{array}$ & chamber & $\begin{array}{l}\text { Rely X, } \\
\text { Clicker, } \\
\text { MaxCem, } \\
\text { Panavia F 2.0, } \\
\text { BisCem, } \\
\text { Bistite II DC }\end{array}$ & $\begin{array}{l}0.3-2 \mathrm{ml} / \mathrm{h} \\
\text { perfusion }\end{array}$ & $\begin{array}{l}\text { all other tested } \\
\text { materials were } \\
\text { cytotoxic }\end{array}$ \\
\hline $\begin{array}{l}\text { Sengun } \\
2010\end{array}$ & $\begin{array}{l}\text { Polyamide } \\
\text { meshes/bovine } \\
\text { fibroblast } \\
\text { pulp- derived } \\
\text { cells }\end{array}$ & $\begin{array}{l}\text { Dentin discs } \\
-(500 \mu \mathrm{m}) \text { - } \\
\text { bovine } \\
\text { incisors. } \\
\text {-treatment: } \\
\text { etching } 50 \% \\
\text { citric } \quad 30 \text { " } \\
\text { for smear } \\
\text { removal, } \\
\text { autoclaved } \\
\left(121^{\circ} \mathrm{C}, \quad 25\right. \\
\text { min) }\end{array}$ & $\begin{array}{l}\text { Customised } \\
\text { Cell } \\
\text { perfusion } \\
\text { chamber }\end{array}$ & $\begin{array}{l}\text { Insertion of } \\
\text { dentin bonding } \\
\text { agents: } \\
\text { G-Bond, } \\
\text { Adper Prompt } \\
\text { Self-Etch, } \\
\text { Clearfil DC } \\
\text { Bond } \\
\text { System, and } \\
\text { Quadrant } \\
\text { University-1- } \\
\text { Bond. }\end{array}$ & $\begin{array}{l}\text { MTT assay } \\
24 \mathrm{~h} \text { after } \\
\text { exposure to } \\
\text { sample } \\
0.3-2 \mathrm{ml} / \mathrm{h} \\
\text { perfusion }\end{array}$ & $\begin{array}{l}\text { UB and } \mathrm{CDCB} \\
\text { were similar to } \\
\text { the control } \\
\text { group }(\mathrm{P}<0.05) \text {. } \\
\text { All other tested } \\
\text { materials were } \\
\text { cytotoxic }\end{array}$ \\
\hline $\begin{array}{l}\text { Schmalz } \\
2014\end{array}$ & $\begin{array}{l}\text { Collagen } \\
\text { hydrogel on } \\
\text { polyamide } \\
\text { meshes/human } \\
\text { fibroblast - } \\
\text { pulp derived } \\
\text { (SV40 large T } \\
\text { antigen } \\
\text { transfected) }\end{array}$ & $\begin{array}{l}\text { Dentin discs } \\
-(200 \mu \mathrm{m}) \text { - } \\
\text { bovine lower } \\
\text { anterior } \\
\text { teeth. }\end{array}$ & $\begin{array}{l}\text { Dentin } \\
\text { barrier test }\end{array}$ & $\begin{array}{l}\text { Insertion of } \\
\text { resin-based } \\
\text { composites } \\
\text { and adhesive: } \\
\text { Tetric } \\
\text { EvoCeram, } \\
\text { N'Durance, } \\
\text { Clearfil SE } \\
\text { Bond. }\end{array}$ & $\begin{array}{l}\text { WST-1 cell } \\
\text { proliferation } \\
\text { assay. } \\
0.3 \mathrm{ml} / \mathrm{h} \\
\text { perfusion }\end{array}$ & $\begin{array}{l}\text { The resin-based } \\
\text { composites } \\
\pm \text { dental } \\
\text { adhesive were } \\
\text { non-toxic with } \\
\text { values similar to } \\
\text { the non-toxic } \\
\text { control. }\end{array}$ \\
\hline
\end{tabular}




\begin{tabular}{|c|c|c|c|c|c|c|}
\hline $\begin{array}{l}\text { Jiang } \\
2016\end{array}$ & $\begin{array}{l}\text { 3D polystyrene } \\
\text { scaffolds } \\
\text { /L929 mouse } \\
\text { fibroblasts }\end{array}$ & $\begin{array}{l}\text { Dentin discs } \\
-(300, \quad 500, \\
1000 \mu \mathrm{m}) \\
\text { human } \\
\text { molars. } \\
\text {-treatment: } \\
70 \% \text { EtoH }\end{array}$ & $\begin{array}{l}\text { Customised } \\
\text { Cell } \\
\text { perfusion } \\
\text { chamber }\end{array}$ & $\begin{array}{l}\text { Insertion of } \\
\text { dental } \\
\text { adhesives: } \\
\text { Vitrebond, } \\
\text { Gluma bond 5, } \\
\text { Gluma Self } \\
\text { Etch, Single } \\
\text { bond } \\
\text { Universal } \\
\text { (self-etch) }\end{array}$ & $\begin{array}{l}\text { MTT assay } \\
24 \mathrm{~h} \text { after } \\
\text { exposure to } \\
\text { sample } \\
0.3 \mathrm{ml} / \mathrm{h} \\
\text { perfusion }\end{array}$ & $\begin{array}{l}\text { Self-etch } \\
\text { materials are } \\
\text { non-toxic. } \\
\text { Vitrebond and } \\
\text { gluma bond } 5 \\
\text { (for } 300 \quad \mu \mathrm{m} \\
\text { dentin } \\
\text { thickness) are } \\
\text { more cytotoxic } \\
\text { than the positive } \\
\text { control. }\end{array}$ \\
\hline
\end{tabular}

Table 2: Customised Cell perfusion chamber studies.

\section{Tooth bud model.}

For this category of experiments, a model for the developing tooth was assembled de novo using mesenchymal cells for the pulp and epithelial cells for dentin. The three articles retrieved used different techniques for the assembly. This was achieved either by encapsulating the cells in a gel drop (CellMatrix) and injecting epithelial cells adjacent to the mesenchymal cells within the CellMatrix [18], or by using GelMa and layering cell sheets of epithelial cells over cells sheets of epithelial cells [19] or by superimposing different concentrations of GelMa: 5\% for the pulp analogue containing mesenchymal cells, and 3\% for the dentin analogue containing epithelial cells layered on top of the 5\% GelMa [20]. Most studies used osteogenic medium for the tooth bud model culture [19,20], the observation period varied from 1 day to 6 weeks, and the cells utilised were all of animal origin. The evaluation of the success of this attempt was performed mostly by histological analysis via Hematoxyline \& Eosin (H\&E) staining, Immunohistochemistry (IHC), immunofluorescence (IF), Polarised Light imaging (Pol) and Atomic Force Microscopy (AFM). The primary outcomes were the successful cell to cell compaction and interactions between epithelial and mesenchymal cells [18,19]. Expression of angiogenic markers, such as CD31, mesenchymal marker Vimentin, dentin markers, such as DSPP, and cell-cell marker E cadherin, were expressed by the interacting cellular populations [20]. The ultimate purpose of these attempts was to present a viable 3D method for tooth replacement through biomimetic tooth formation. 


\begin{tabular}{|c|c|c|c|c|c|c|}
\hline $\begin{array}{l}\text { Author, } \\
\text { year }\end{array}$ & $\begin{array}{l}\text { Pulp analogue } \\
\text { (Scaffold/cells) }\end{array}$ & $\begin{array}{l}\text { Dentin } \\
\text { analogue }\end{array}$ & $\begin{array}{l}\text { Asse } \\
\text { mbly }\end{array}$ & $\begin{array}{l}\text { Interventio } \\
\mathrm{n}\end{array}$ & $\begin{array}{l}\text { Methods/ } \\
\text { Biological } \\
\text { endpoints }\end{array}$ & Efficacy measurement \\
\hline $\begin{array}{l}\text { Nakao } \\
2007\end{array}$ & $\begin{array}{l}\text { Cellmatrix type } \\
\text { I-A / Mice } \\
\text { mesenchymal } \\
\text { cells }\end{array}$ & $\begin{array}{l}\text { Epithelial } \\
\text { single cells } \\
\text { injected } \\
\text { adjacent to } \\
\text { the } \\
\text { mesenchym } \\
\text { al cell } \\
\text { aggregate }\end{array}$ & $\begin{array}{l}\text { Pipett } \\
\text { ing } \\
\text { cells- } \\
\text { direct } \\
\text { cell- } \\
\text { cell } \\
\text { conta } \\
\text { ct }\end{array}$ & $\begin{array}{l}\text { Organ } \\
\text { culture for } \\
2+14 d\end{array}$ & $\mathrm{H} \& \mathrm{E}$ & $\begin{array}{l}1 \mathrm{~d} \text { of organ culture: } \\
\text {-formation of a } \\
\text { tooth germ } \\
\text {-appropriate } \\
\text { compartmentalization between } \\
\text { epithelial and mesenchymal cells } \\
\text {-cell-to-cell compaction }\end{array}$ \\
\hline $\begin{array}{l}\text { Montei } \\
\text { ro } 2016\end{array}$ & $\begin{array}{l}\text { 5\% GelMA } \\
\text { /Porcine dental } \\
\text { mesenchymal } \\
\text { (DM) } \\
\text { progenitor cells }\end{array}$ & $\begin{array}{l}\text { The Dental } \\
\text { Epithelial } \\
\text { (DE) Cell } \\
\text { sheet layers }\end{array}$ & $\begin{array}{l}\text { Layer } \\
\text { ing } \\
\text { cell } \\
\text { sheets } \\
\text { (CS) } \\
\text { of } \\
\text { DM- } \\
\text { DE } \\
\text { over } \\
\text { polym } \\
\text { erised } \\
\text { DM } \\
5 \% \\
\text { GelM } \\
\text { A }\end{array}$ & $\begin{array}{l}\text { Osteogeni } \\
\text { c medium } \\
1,4,7,12 \mathrm{sd}\end{array}$ & $\begin{array}{l}\text { H\&E, IHC } \\
\text { and IF } \\
\text { analyses } \\
\text { IHC (H\&E, } \\
\text { FAK, TEN } \\
\text { and SYN4 } \\
\text { Pol } \\
\text { (polarized } \\
\text { light } \\
\text { imaging) } \\
\text { IF (Sonic } \\
\text { Hedgehog, } \\
\text { BMP-2, } \\
\text { RunX2) }\end{array}$ & $\begin{array}{l}\text { in vitro cultured multilayered DE- } \\
\text { DM CSs expressed appropriate } \\
\text { tooth marker expression patterns } \\
\text { including SHH, BMP2, RUNX2, } \\
\text { tenascin and } \\
\text { syndecan, which normally direct } \\
\text {-DE-DM interactions, } \\
\text {-DM cell condensation, and } \\
\text {-dental cell differentiation. }\end{array}$ \\
\hline
\end{tabular}




\begin{tabular}{|l|l|l|l|l|l|l|}
\hline Smith & $5 \%$ GelMA / & pDE- & Layer & preculture & AFM & H\&E: ECM increase over time \\
(cell differentiation)
\end{tabular}

Table 3: Tooth bud model studies.

\section{$\underline{\text { 3D dentin/pulp complex manufactured by tissue engineering. }}$}

This group is the most diverse, with the most recent studies in terms of year of publication. The dentin/pulp complexes of this category are comprised of: spheres within rings with different stiffness values [45], slices of dentin with the preservation of the dental pulp [37], cells encapsulated in fibrin including Growth factors enhancing angiogenesis (VEGF) accompanied with BMP-2 coated dentin discs [36], stacking fibrinogen - of various concentrations - in a bioprinting process within a polycaprolactone frame for dentin and the pulp [47], hanging culture inserts dividing two compartments - a dentin analogue and a pulp analogue - through a membrane with a dentin slice [35] and lastly, a three-dimensional tooth on a chip assembly with two perfusable compartments representing dentin and the dental pulp. In this category cellular populations were all of human origin, mostly DPSCs [35,36,45,47] and SCAP [25], while Hadjichristou et al. used a combination of HUVEC and SCAP for the pulp compartment and DPSCs for the dentin compartment [35]. The observation period of these experiments varied from 3 days [37] up to 4 weeks [45] and the main outcome of these studies was to evaluate the feasibility of a dentin/pulp complex implementation via mineral deposition quantification [45,47], 
marker gene expression for angiogenic ( $v W F, V E G F, P E C A M-1, V E G F R-2, A N G P T-1, T I E-2)$ [35-37] as well as odontogenic markers (BSP, DMP-1, OCN and CBFA, DSPP, RunX2, BMP-2) $[35,36,47]$ and thyrotropinreleasing hormone degrading enzyme (TRHDE) and syndecan3 which are highly expressed in the natural pulp [45]. Some of the constructs were further utilised to deduce the cytotoxicity of dental materials such as eluates of resin monomers (HEMA, TEGDMA) [35] or of resin monomer (HEMA) and phosphoric acid [25] using techniques such as MTT, LDH and Live cell imaging. All results seemed promising in their utilisation as 3D biocompatibility investigation tools, all with potential improvements and high output capabilities.

\begin{tabular}{|c|c|c|c|c|c|c|}
\hline $\begin{array}{l}\text { Author } \\
\text {, year }\end{array}$ & $\begin{array}{l}\text { Pulp } \\
\text { analogue }\end{array}$ & $\begin{array}{l}\text { Dentin } \\
\text { analogue }\end{array}$ & Assembly & Intervention & $\begin{array}{l}\text { Methods/ } \\
\text { Biological } \\
\text { endpoints }\end{array}$ & Efficacy measurement \\
\hline $\begin{array}{l}\mathrm{Qu} \\
2015\end{array}$ & $\begin{array}{l}\text { low } \\
\text { stiffness } \\
\text { nanofibrou } \\
\mathrm{s} \quad(\mathrm{NF}) \\
\text { gelatin } \\
\text { scaffold } \\
\text { /DPSCs } \\
\text { (sphere) }\end{array}$ & $\begin{array}{l}\text { high } \\
\text { stiffness } \\
\text { (NF) gelatin } \\
\text { scaffold } \\
\text { /DPSCs } \\
\text { (ring shape) }\end{array}$ & $\begin{array}{l}\text { Mechanica } \\
1 \text { seamless } \\
\text { assembly } \\
\text { of the } \\
\text { sphere } \\
\text { within the } \\
\text { ring }\end{array}$ & $\begin{array}{l}\text { differential } \\
\text { medium for } \\
4 \text { weeks }\end{array}$ & $\begin{array}{l}\text { H\&E, } \\
\text { Von kossa, } \\
\text { thyrotropi } \\
\text { n-releasing } \\
\text { hormone } \\
\text { degrading } \\
\text { enzyme } \\
\text { (TRHDE), } \\
\text { syndecan3 } \\
\text { (SDC3) }\end{array}$ & $\begin{array}{l}\text { cell density in the central } \\
\text { area was higher than in } \\
\text { the peripheral area of the } \\
\text { construct. } \\
\text { von Kossa: } \\
\text { mineralization in the } \\
\text { high-stiffness area } \\
\text { the expression of } \\
\text { (TRHDE) and (SDC3), } \\
\text { (highly expressed in } \\
\text { natural pulp) were } \\
\text { significantly higher in the } \\
\text { central area than in } \\
\text { the peripheral area. }\end{array}$ \\
\hline
\end{tabular}




\begin{tabular}{|c|c|c|c|c|c|c|}
\hline $\begin{array}{l}\text { Seang } \\
2018\end{array}$ & $\begin{array}{l}\text { Natural } \\
\text { pulp }\end{array}$ & $\begin{array}{l}\text { Dentin discs } \\
\text { ( } 2 \mathrm{~mm} \text { thick) } \\
\text { from human } \\
3^{\text {rd }} \text { molars }\end{array}$ & $\begin{array}{l}\text { Natural } \\
\text { slices from } \\
\text { parts of } \\
\text { tooth } \\
\text { containing } \\
\text { both } \\
\text { dentin and } \\
\text { pulp. }\end{array}$ & $\begin{array}{l}\text { slices were } \\
\text { cultured } \\
\text { without } \\
\text { (control) or } \\
\text { with iloprost } \\
\text { for } 1 \text { or } 3 \\
\text { days. } \\
\text { Serum-free } \\
\text { DMEM was } \\
\text { used as the } \\
\text { culture } \\
\text { medium in } \\
\text { all } \\
\text { experimenta } \\
1 \text { conditions }\end{array}$ & $\begin{array}{l}\text { Confocal } \\
\text { microscop } \\
\text { y } \\
\text { (live/dead } \\
\text { staining) } \\
\text { IHC and } \\
\text { IF (vWF, } \\
\text { VEGF, } \\
\text { Col-1), } \\
\text { H\&E } \\
\text { counterstai } \\
\text { ning }\end{array}$ & $\begin{array}{l}\text { Cells viability was } \\
\text { unaffected at } 1 \text { and } 3 \\
\text { days } \\
\text { Iloprost promoted } \\
\text { angiogenesis } \\
\text { vWF and vEGF } \\
\text { demonstrated } \\
\text { significant increase } \\
\text { at both } 1 \text { and } 3 \text { days. } \\
\text { Iloprost } \\
\text { Collagen } \quad \text { Stimulated } \\
\text { shown by masson's } \\
\text { trichrome staining and } \\
\text { Col-1 IF. }\end{array}$ \\
\hline $\begin{array}{l}\text { Aksel } \\
2018\end{array}$ & $\begin{array}{l}\text { Fibrin gel } \\
+\mathrm{VEGF} / \\
\text { Human } \\
\text { DPSCs } \\
\text { and VEGF }\end{array}$ & $\begin{array}{l}\text { BMP-2 } \\
\text { coated } \\
\text { demineraliz } \\
\text { ed human } \\
\text { dentine } \\
\text { discs (dd- } \\
\text { BMP-2). } \\
\text { Dentin } \\
\text { treatment: } \\
\text { betadine for } \\
30 \text { min and } \\
1.5 \% \\
\text { sodium }\end{array}$ & $\begin{array}{l}\text { Fibrin gel- } \\
\text { VEGF } \\
\text { inserted } \\
\text { into dd- } \\
\text { BMP-2 }\end{array}$ & $\begin{array}{l}\text { DPSCs in } \\
\text { the absence } \\
\text { or presence } \\
\text { of VEGF } \\
\text { and BMP-2 } \\
\text { for } 28 \mathrm{~d}\end{array}$ & $\begin{array}{l}\text { MTT and } \\
\text { Live\&Dea } \\
\text { d assays } \\
\text { ELISA for } \\
\text { release } \\
\text { profiles of } \\
\text { VEGF and } \\
\text { BMP-2 } \\
\text { RT-qPCR } \\
\text { analysis: } \\
\text { angiogenic } \\
\text { and }\end{array}$ & $\begin{array}{l}\text { Higher expressions of } \\
\text { PECAM as an angiogenic } \\
\text { factor, and BSP, DMP-1, } \\
\text { OCN and CBFA as } \\
\text { odontogenic factors were } \\
\text { observed in 3D culture } \\
\text { model as compared to the } \\
\text { other fg/dd combinations } \\
\text { and the monolayer } \\
\text { control group }\end{array}$ \\
\hline
\end{tabular}




\begin{tabular}{|c|c|c|c|c|c|c|}
\hline & & $\begin{array}{l}\text { hypochlorite } \\
\text { for } 10^{\prime} \\
\text { Soaked in } \\
17 \% \text { EDTA/ } \\
15^{\prime} \text {. }\end{array}$ & & & $\begin{array}{l}\text { odontogen } \\
\text { ic } \\
\text { differentiat } \\
\text { ion } \\
\text { markers }\end{array}$ & \\
\hline $\begin{array}{l}\text { Han } \\
2019\end{array}$ & $\begin{array}{l}\text { Fibrinogen } \\
(5 \mathrm{mg} / \mathrm{ml}) \text { - } \\
\text { bio- } \\
\text { ink/human } \\
\text { DPSCs }\end{array}$ & $\begin{array}{l}\text { fibrinogen } \\
\text { (20mg/ml)- } \\
\text { bio-ink } \\
\text { (Polycaprola } \\
\text { ctone for 3D } \\
\text { overall } \\
\text { shape of the } \\
\text { tooth) }\end{array}$ & $\begin{array}{l}\text { 3D } \\
\text { construct } \\
\text { produced } \\
\text { by } \\
\text { repeated } \\
\text { printing } \\
\text { process } \\
\text { with } \\
\text { stacking. }\end{array}$ & $\begin{array}{l}\text { cultured } \\
\text { with } \\
\text { odontogenic } \\
\text { differentiati } \\
\text { on medium } \\
\text { for } 15 \text { days }\end{array}$ & $\begin{array}{l}\text { Live } \\
\text { \&dead } \\
\text { staining } \\
\text { Alamar } \\
\text { blue } \\
\text { Alizarin } \\
\text { red } \\
\text { staining } \\
\text { mRNA } \\
\text { expression } \\
\text { of } \\
\text { (DMP-1) } \\
\text { and } \\
\text { (DSPP) }\end{array}$ & $\begin{array}{l}\text { mineral deposition was } \\
\text { locally observed only in } \\
\text { the outer region, and not } \\
\text { in the central region of } \\
\text { the pulp tissue. This } \\
\text { result confirmed that the } \\
\text { designed 3D bioprinting } \\
\text { process could induce } \\
\text { localized odontogenic } \\
\text { differentiation in a } \\
\text { designed 3D space, } \\
\text { specifically patient- } \\
\text { specific shaped } 3 \mathrm{D} \\
\text { dentin-pulp complexes. }\end{array}$ \\
\hline
\end{tabular}




\begin{tabular}{|c|c|c|c|c|c|c|}
\hline & & & & & SEM & \\
\hline $\begin{array}{l}\text { Hadjic } \\
\text { hristou } \\
2019\end{array}$ & $\begin{array}{l}\text { Collagen } \\
\text { I/Fibrin } \\
\text { hydrogel } \\
\text { /human } \\
\text { HUVEC/S } \\
\text { CAP co- } \\
\text { cultured } \\
\text { cells }\end{array}$ & $\begin{array}{l}\text { Human } \\
\text { DPSCs on } \\
\text { membranes } \\
\text { of hanging } \\
\text { culture } \\
\text { inserts } \\
\text { covered by a } \\
\text { disc-shaped } \\
\text { human } \\
\text { treated } \\
\text { dentin } \\
\text { matrix } \\
\text { (hTDM) }\end{array}$ & $\begin{array}{l}\text { Mechanica } \\
1 \\
\text { placement } \\
\text { of the } \\
\text { hanging } \\
\text { culture } \\
\text { insert } \\
\text { (dentin } \\
\text { analogue) } \\
\text { in } 24 \text {-well } \\
\text { plates } \\
\text { containing } \\
\text { pulp } \\
\text { analogue }\end{array}$ & $\begin{array}{l}\text { resin } \\
\text { monomers } \\
\text { (TEGDMA/ } \\
\text { HEMA) and } \\
\text { Bacterial } \\
\text { endotoxin } \\
\text { (LPS) } \\
\text { inserted } \\
\text { through the } \\
\text { hanging } \\
\text { culture } \\
\text { insert }\end{array}$ & $\begin{array}{l}\text { MTT } \\
\text { LDH } \\
\text { Real time } \\
\text { PCR for } \\
\text { angiogene } \\
\text { sis-related } \\
\text { genes } \\
\text { (VEGFa, } \\
V E G F R-2, \\
A N G P T-1, \\
T I E-2 \text { and } \\
P E C A M- \\
1)\end{array}$ & 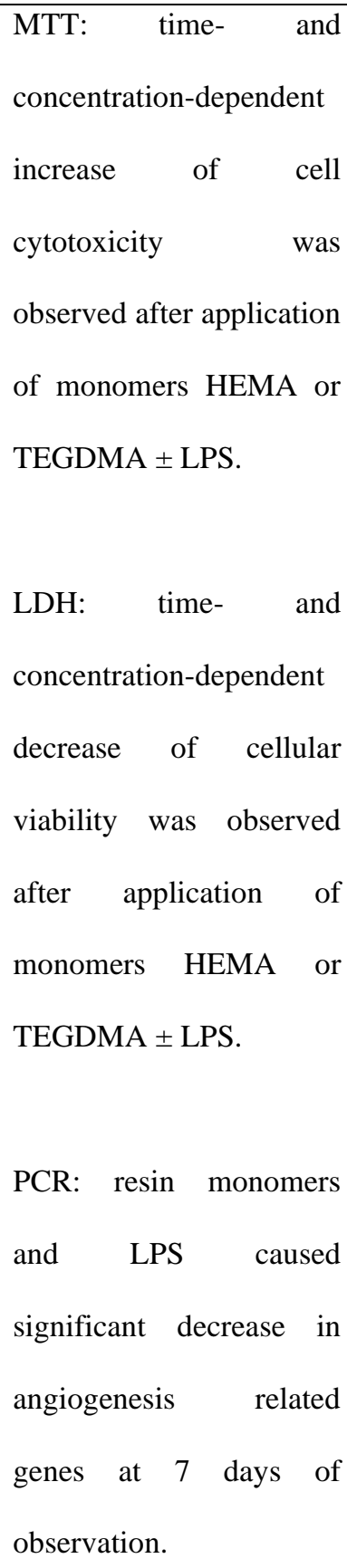 \\
\hline
\end{tabular}




\begin{tabular}{|c|c|c|c|c|c|c|}
\hline $\begin{array}{l}\text { França } \\
2019\end{array}$ & $\begin{array}{l}\text { Perfusable } \\
\text { chamber } \\
\text { in PDMS } \\
\text { mold/ } \\
\text { SCAP }\end{array}$ & $\begin{array}{l}500 \mu \mathrm{m} \\
\text { human } \\
\text { dentin } \\
\text { fragments } \\
\text { (17\% EDTA } \\
\text { for } 45 \text { ' to } \\
\text { remove the } \\
\text { smear layer, } \\
\text { thoroughly } \\
\text { rinsed with } \\
\text { water) }\end{array}$ & $\begin{array}{l}\text { Separation } \\
\text { of pulp } \\
\text { side and } \\
\text { cavity side } \\
\text { by the } \\
\text { dentin } \\
\text { fragment } \\
\text { within the } \\
\text { PDMS } \\
\text { mold }\end{array}$ & $\begin{array}{l}\text { a. } 10 \mathrm{mM} \text {, } \\
\text { (b) } 37 \% \\
\text { phosphoric } \\
\text { acid gel } \\
\text { (PA) } \\
\text { used to etch } \\
\text { the dentin } \\
\text { for } 15 \text { s, and } \\
\text { (c) } 35 \% \text { PA } \\
\text { plus Adper } \\
\text { Single Bond } \\
2 \\
\text { applied } \\
\text { through the } \\
\text { of } \\
\text { device. }\end{array}$ & $\begin{array}{l}\text { Live-cell } \\
\text { imaging to } \\
\text { test } \\
\text { cytotoxicit } \\
\text { y } \\
\text { (incubatio } \\
\text { n with } 50 \\
\text { nM of } \\
\text { Helix NP } \\
\text { NIR). } \\
\text { Gelatinoly } \\
\text { tic activity } \\
\text { by } \\
\text { fluoresce }\end{array}$ & $\begin{array}{l}\text { Live-cell imaging: Each } \\
\text { tested material elicited } \\
\text { apparent cellular injury } \\
\text { with as early as } 24 \mathrm{~h} \text {, } \\
\text { visible reduction in cell } \\
\text { number relative to the } \\
\text { untreated controls } \\
\text { Green fluorescence, } \\
\text { indicative of MMP } \\
\text { activity, was visible after } \\
24 \mathrm{~h} \text { and peaked after } 48 \\
\mathrm{~h} \text {. }\end{array}$ \\
\hline
\end{tabular}

Table 4: 3D dentin/pulp complex manufactured by tissue engineering.

Entire tooth culture.

The four studies utilising the entire tooth culture have followed a similar implementation protocol based on the first reported study by Téclès et al. [14]. In this case, freshly extracted teeth with open apical foramens were fixed and cultured in tissue plates with their apical parts immersed in culture medium, allowing the diffusion of the medium to the dental tissues for up to 4 weeks [14]. After the efficacy of the method was sufficiently studied through histological analyses and IHC [14], additional studies followed, aiming to investigate the reaction of the pulp after the application of dental materials within cavities of the suspended teeth. Among the tested materials, the retrieved articles included Mineral Trioxide (MTA) [15,17], Calcium hydroxide [15], and Biodentine [44]. The methods of evaluation for the pulp response after the application of dental materials comprised a histological (H\&E staining, Gram staining) [17,44] and an IHC evaluation for collagen I, Osteonectin, dentine 
sialoprotein $(D S P P)$, nestin $[15,44]$. Through the results, it was possible to show that this method -the entire tooth culture- was able to recapitulate some of the responses of the natural teeth to the same materials when applied in vivo [15]. It could be recognised that this is an easily reproducible method without the need to regenerate the natural tooth de novo, as is the case with most of the other categories in this review. It also comprises a smart tool to test dental materials in direct contact with the three-dimensional native tissue for the amount of time that the tooth can uptake nutrients from the surrounding culture medium.

\begin{tabular}{|c|c|c|c|c|}
\hline $\begin{array}{l}\text { Author, } \\
\text { Year }\end{array}$ & $\begin{array}{l}\text { Dentin/Pulp complex } \\
\text { preparation }\end{array}$ & Intervention & $\begin{array}{l}\text { Methods/ } \\
\text { Biological } \\
\text { endpoints }\end{array}$ & Efficacy measurement \\
\hline $\begin{array}{l}\text { Téclès } \\
2005\end{array}$ & $\begin{array}{l}\text { Teeth were cultured in } \\
\text { four-well-tissue plates. } \\
\text { The crowns were fixed } \\
\text { to the cover with sterile } \\
\text { wax and the apical part } \\
\text { of the teeth was dipped } \\
\text { in the culture medium. }\end{array}$ & \pm cavities & $\begin{array}{l}\text { Histology: } \mathrm{H} \& \mathrm{E} \\
\text { staining }\end{array}$ & $\begin{array}{l}1 \text { day, the BrdU was localised to } \\
\text { the nuclei of cells in the } \\
\text { perivascular area and decreased } \\
\text { in those away from the cavity. } \\
2 \text { weeks: labelled cells were } \\
\text { seen in the vicinity of the cavity. } \\
4 \text { weeks: the immunolabelling } \\
\text { was localised to the cavity area } \\
\text { only. } \\
\text { Control teeth without cavities or } \\
\text { with shallow dentine cavities } \\
\text { did not show any perivascular } \\
\text { labelling after culture. }\end{array}$ \\
\hline $\begin{array}{l}\text { Téclès } \\
2008\end{array}$ & $\begin{array}{l}\text { After cavities } \\
\text { preparations and } \\
\text { restorations, the teeth } \\
\text { were fixed by the } \\
\text { crowns to a wire and } \\
\text { were suspended in the } \\
\text { culture medium in 12- }\end{array}$ & $\begin{array}{l}\text { Cavity was } \\
\text { gently dried } \\
\text { and } \\
\text { immediately } \\
\text { with: } \\
\text {-Mineral } \\
\text { Trioxide }\end{array}$ & $\begin{array}{l}\text { Histology: } \mathrm{H} \& \mathrm{E} \\
\text { staining } \\
\text { IHC: Collagene } \\
\text { type I, Dentin } \\
\text { sialoprotein, and } \\
\text { Nestin }\end{array}$ & $\begin{array}{l}\text { Histological staining after direct } \\
\text { pulp capping with Calcium } \\
\text { Hydroxide XR1 or } \\
\text { MTA revealed early and } \\
\text { progressive mineralized foci } \\
\text { formation containing BrdU- } \\
\text { labeled sequestered cells. }\end{array}$ \\
\hline
\end{tabular}




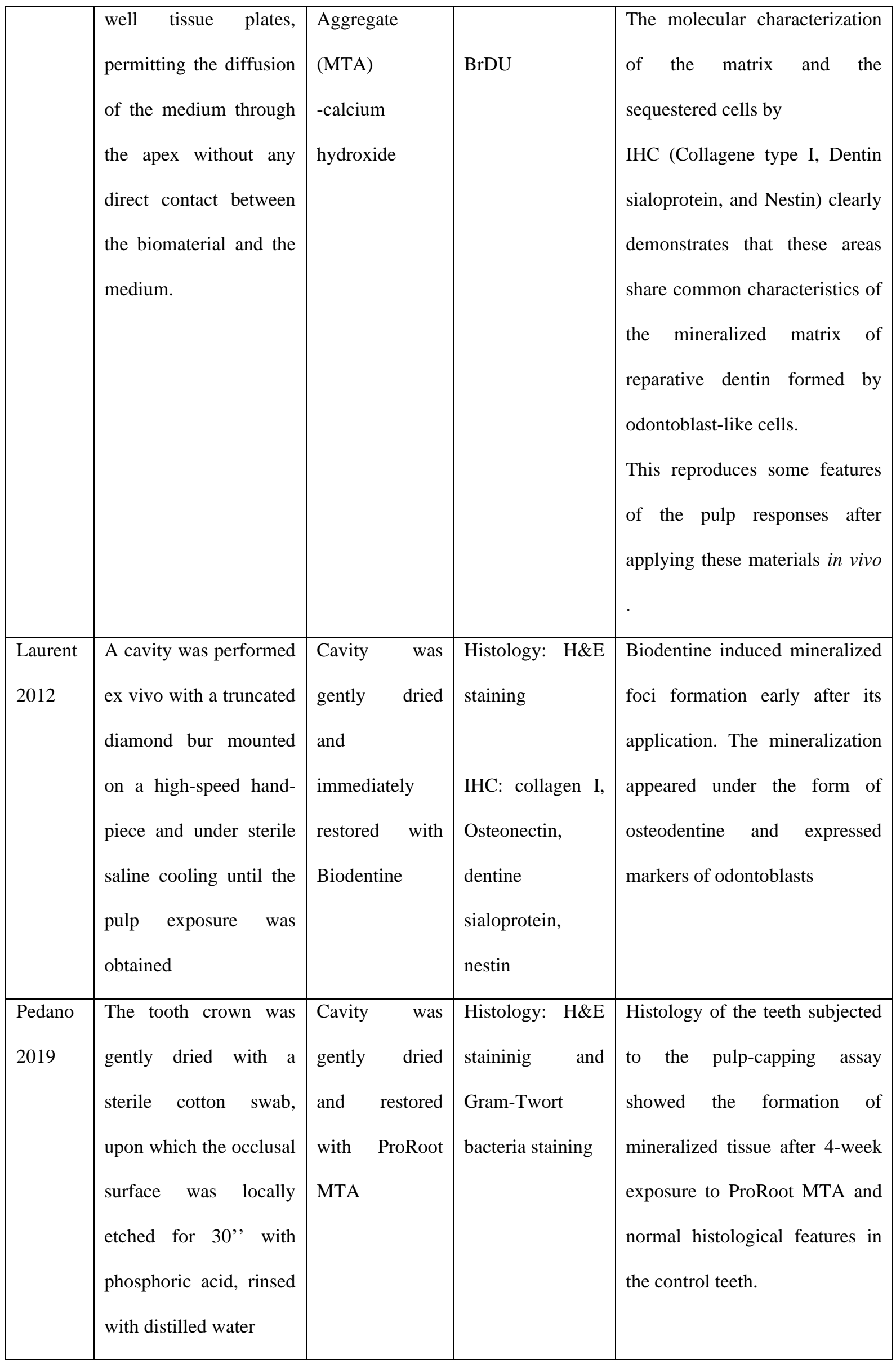




\begin{tabular}{|l|l|l|l|}
\hline and gently dried. The \\
crowns were hanged in \\
the wells of a 24 plate, \\
using steel wire and \\
flowable composite, \\
containing tooth-culture \\
medium.
\end{tabular} \mid

Table 5: Entire tooth culture studies.

Tooth slice organ culture.

The tooth slice organ culture, has been implemented by a research group at the university of Birmingham. This group has come up with a protocol where teeth of rat or human origin, were embedded in a semisolid medium, firstly mentioned by Sloan et al. in 1998[30]. This embedded tissue was then transferred to a Millipore membrane and was let to float on culture medium. Following a certain time period, the embedded tissue was fixed in paraffin and histologically examined. After the investigation of the performance of this method in terms of cell viability and maintenance of the morphological characteristics of the dentin/pulp complex without any exogenous additions, this model received further additions. This development consisted of the introduction of growth factors, dental materials or even an award winning tensile/compressive force testing assembly. The endpoints of evaluation were mainly through histomorphometric analyses and H\&E staining [30-32,34,46] and in one occasion, through Semi-quantitative reverse transcriptase polymerase chain reaction (Sq-RT-PCR) analysis [34]. Through the results, it was possible to show that this method -the tooth slice organ culture - was able to maintain the histological characteristics of the natural dentin/pulp tissue for up to 14 days when interventions were excluded [30]. This model has proved to be of multiple uses. By the introduction of different exogenous stimuli, it was possible to monitor tissue repair responses after the introduction of growth factors [31]. The same model was also useful as an in vitro cytotoxicity screening tool for dental materials [46] or even as a dentin/pulp response model to orthodontic force application [34]. In this experimental setup, similar to the entire tooth culture model, the natural tissues are utilized eliminating the need to recapitulate the dentin/pulp complex from scratch.

\begin{tabular}{|l|l|l|l|l|}
\hline Author, & Dentin/Pulp complex & Intervention & Methods/ & Efficacy measurement / \\
year & preparation & & Biological & outcomes \\
\hline
\end{tabular}




\begin{tabular}{|c|c|c|c|c|}
\hline & & & endpoints & \\
\hline $\begin{array}{l}\text { Sloan } \\
1998\end{array}$ & $\begin{array}{l}\text { Tooth slice }-(2 \mathrm{~mm})- \\
\text { from maxillary and } \\
\text { mandibular rat incisors. } \\
\text { The tooth slices were } \\
\text { embedded in low } \\
\text { melting point agar, in } \\
\text { 96-well plates. } \\
\text { When the agar was } \\
\text { semisolid, the slices } \\
\text { were transferred on } \\
\text { Millipore filters, floating } \\
\text { in DMEM in Trowel- } \\
\text { type cultures in Petri } \\
\text { Dishes. } \\
\text { 2-14 days incubation } \\
\text { by: paraffin embedment }\end{array}$ & & $\begin{array}{l}\text { Histological } \\
\text { examination. } \\
\text { Viability } \\
\text { assessment with } \\
\text { acridine orange. } \\
\text { Radiolabelling } \\
\text { with proline for } \\
\text { ECM synthesis. } \\
\text { TEM (transmission } \\
\text { electron } \\
\text { microscopy) }\end{array}$ & $\begin{array}{l}\text { The integrity of the dentin/pulp } \\
\text { complex was maintained for } \\
\text { the total experimental period } \\
\text { (14d). } \\
\text { Pulp cells and odontoblasts } \\
\text { were vital after all culture } \\
\text { periods. } \\
\text { At } 14 \mathrm{~d} \text { in culture, } \\
\text { radiolabelling was greater than } \\
\text { at } 7 \mathrm{~d} \text { within predentin. } \\
\text { TEM: cell architecture } \\
\text { appeared to correlate well with } \\
\text { that seen in control } \\
\text { uncultured tissues. }\end{array}$ \\
\hline Sloan 1999 & $\begin{array}{l}\text { Tooth slice }-(2 \mathrm{~mm})- \\
\text { from rat incisors. } \\
\text { The tooth slices were } \\
\text { embedded in low } \\
\text { melting point agar, in } \\
\text { 96-well plates. }\end{array}$ & $\begin{array}{l}\text { Introduction of: } \\
\text { Agarose beads } \\
\text { with isoforms of } \\
\text { TGF- } \beta 1,2 \text { or } 3 \\
\text { were placed on } \\
\text { the edge of the } \\
\text { mineralized } \\
\text { tissue }\end{array}$ & $\begin{array}{l}\text { Histological } \\
\text { examination: } \\
\text { hematoxylin and } \\
\text { eosin (H\&E) } \\
\text { staining. } \\
\text { Morphometrical } \\
\text { analysis: }\end{array}$ & $\begin{array}{l}\text { At areas without agarose } \\
\text { beads, the normal architecture } \\
\text { of dentin/pulp complex was } \\
\text { maintained. } \\
\text { Similar to controls, TGF- } \beta_{2} \text {, } \\
\text { caused no significant } \\
\text { differences. }\end{array}$ \\
\hline
\end{tabular}




\begin{tabular}{|c|c|c|c|c|}
\hline & $\begin{array}{l}\text { When the agar was } \\
\text { semisolid, the slices } \\
\text { were transferred on } \\
\text { Millipore filters, floating } \\
\text { in DMEM in 'Trowel- } \\
\text { type' cultures in Petri } \\
\text { Dishes. } \\
7 \text { days incubation } \\
37 \mathrm{C} / 5 \% \text { CO2 followed } \\
\text { by: paraffin embedment }\end{array}$ & $\begin{array}{l}\text { corresponding } \\
\text { to the } \\
\text { odontoblast } \\
\text { layer. }\end{array}$ & $\begin{array}{l}\text { subodontoblast } \\
\text { layer cell counting } \\
\text { in areas with or } \\
\text { without the agarose } \\
\text { beads. }\end{array}$ & $\begin{array}{l}\text { TGF- } \beta_{1} \text { and TGF- } \beta_{3} \text { caused } \\
\text { similar differences such as an } \\
\text { increased ECM secretion and } \\
\text { subodontoblast cell density at } \\
\text { the site of application which } \\
\text { was observed for almost } 70 \% \\
\text { of the samples. These two } \\
\text { growth factors can stimulate } \\
\text { dentinogenic effects in } \\
\text { odontoblasts in vitro. }\end{array}$ \\
\hline Murray & $\begin{array}{l}\text { The tooth slices were } \\
\text { embedded in low } \\
\text { melting point agar, in } \\
\text { 96-well plates. } \\
\text { When the agar was } \\
\text { semisolid, the slices } \\
\text { were transferred on } \\
\text { Millipore filters, floating } \\
\text { in DMEM in Trowel- } \\
\text { type cultures in Petri } \\
\text { Dishes. } \\
\text { incubation } 37 \mathrm{C} / 5 \% \mathrm{CO} 2\end{array}$ & $\begin{array}{l}\text { Introduction of } \\
\text { dental materials: } \\
\text { Salicylic acid, } \\
\text { Calcium } \\
\text { hydroxide, } \\
\text { Kalzinol zinc } \\
\text { oxide eugenol, } \\
\text { high-mercury } \\
\text { Amalgam, } \\
\text { Prime\&Bond, } \\
\text { Dycal, Barium } \\
\text { sulphate, } \\
\text { Hypocal, } \\
\text { Scotchbond, } \\
\text { and One-step. }\end{array}$ & $\begin{array}{l}\text { Histological } \\
\text { examination: H\&E } \\
\text { staining. } \\
\text { Histomorphometric } \\
\text { analysis: cell } \\
\text { number counting } \\
\text { within the } \\
\text { dentin/pulp } \\
\text { complex. }\end{array}$ & $\begin{array}{l}\text { For samples without dental } \\
\text { materials, the normal } \\
\text { architecture of dentin/pulp } \\
\text { complex was maintained for } \\
\text { the total study period. } \\
\text { The dental materials caused } \\
\text { cytotoxicity in the following } \\
\text { order (from highest to the } \\
\text { lowest ): } \\
\text { Salicylic acid, Calcium } \\
\text { hydroxide, Kalzinol zinc oxide } \\
\text { Sulphate, } \\
\text { eugenol, high-mercury } \\
\text { Amalgam, }\end{array}$ \\
\hline
\end{tabular}




\begin{tabular}{|c|c|c|c|c|}
\hline & $\begin{array}{l}\text { followed by: paraffin } \\
\text { embedment. }\end{array}$ & & & $\begin{array}{l}\text { These effects were only } \\
\text { detectable on the } 10^{\text {th }} \text { day of } \\
\text { experimentation. }\end{array}$ \\
\hline $\begin{array}{l}\text { Dobie } \\
2002\end{array}$ & $\begin{array}{l}\text { Tooth slice }-(0.5 \mathrm{~mm})- \\
\text { from human } 3^{\text {rd }} \text { molars. } \\
\text { The tooth slices were } \\
\text { cultured on the base of a } \\
\text { petri dish, with the } \\
\text { application of low } \\
\text { melting point agar. } \\
7 \text { days of incubation } \\
37 \mathrm{C} / 5 \% \text { CO } 2 \text { followed } \\
\text { by: paraffin embedment. }\end{array}$ & $\begin{array}{l}\text { Introduction of: } \\
\text { alginate } \\
\text { hydrogels with } \\
\text { different } \\
\text { concentrations } \\
\text { of TGF- } \beta 1 \text {, } \\
\pm \text { acid treatment, } \\
\pm \quad \text { TGF- } \beta 1 \\
\text { antibodies. }\end{array}$ & $\begin{array}{l}\text { Histological } \\
\text { examination: H\&E } \\
\text { staining. } \\
\text { Predentin width } \\
\text { measurement in } \\
\text { each tooth slice. }\end{array}$ & $\begin{array}{l}\text { For samples without TGF- } \beta \text { or } \\
\text { antibodies, the normal } \\
\text { architecture of dentin/pulp } \\
\text { complex was maintained for } \\
\text { the total study period. } \\
\text { Acid treatment and TGF- } \beta \\
\text { caused reactionary and } \\
\text { reparative dentinogenesis. }\end{array}$ \\
\hline $\begin{array}{l}\text { Dhopatkar } \\
2005\end{array}$ & $\begin{array}{l}\text { Specimens from } \\
\text { mandibles of rat incisors } \\
-2 \mathrm{~mm} \text { thick sections } \\
\text { cultured in Petri Dishes. } \\
5 \text { days of incubation } \\
37 \mathrm{C} / 5 \% \text { CO2 followed } \\
\text { by: paraffin embedment. } \\
3 \text { days of incubation } \\
37 \mathrm{C} / 5 \% \text { CO2 followed } \\
\text { by: RNA isolation }\end{array}$ & $\begin{array}{l}\text { Introduction of } \\
\text { tensile or } \\
\text { compressive } \\
\text { forces (50g) to } \\
\text { specimens } \\
\text { through springs. }\end{array}$ & $\begin{array}{l}\text { Histological } \\
\text { examination: H\&E } \\
\text { staining followed } \\
\text { by cell number } \\
\text { counting. } \\
\text { Semi-quantitative } \\
\text { reverse } \\
\text { transcriptase } \\
\text { PCR for gene } \\
\text { expression } \\
\text { analysis. }\end{array}$ & $\begin{array}{l}\text { When no forces were applied, } \\
\text { dental and supporting tissues } \\
\text { maintained a healthy } \\
\text { appearance. } \\
\text { Force application induced an } \\
\text { increase in pulp fibroblast } \\
\text { density. } \\
\text { Force application also induced } \\
\text { upregulation of Proliferating } \\
\text { Cell Nuclear Antigen (PCNA), } \\
\text { c-Myc, Collagen } 1 \alpha \text {, TGF- } \beta 1 \\
\text { and alkaline phosphatase and }\end{array}$ \\
\hline
\end{tabular}




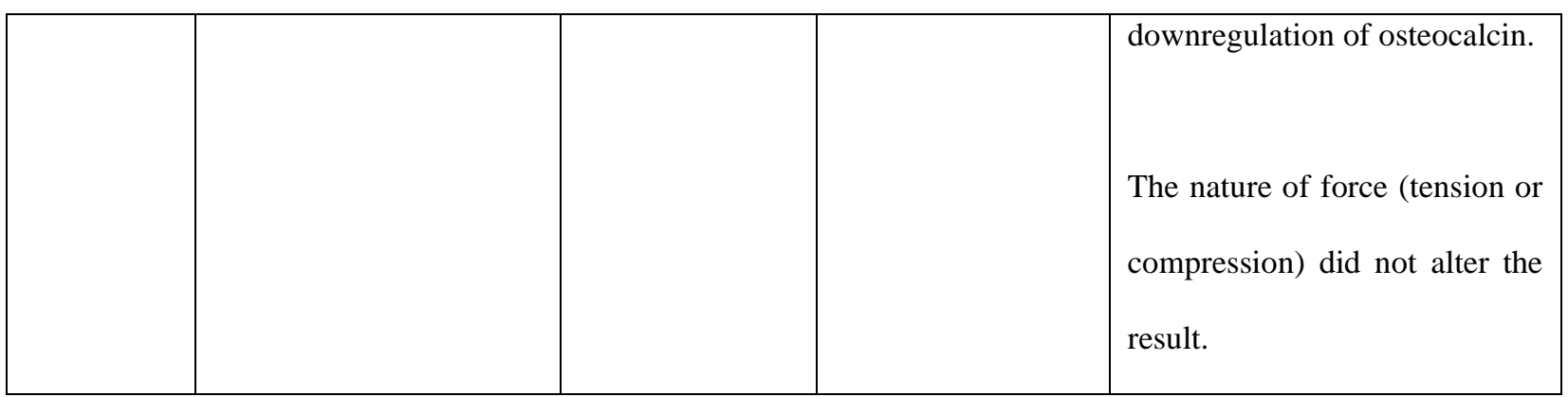

Table 6: Tooth slice organ culture studies.

\section{Discussion}

The formation of a valid and easily reproducible 3D dentin/pulp complex holds a critical aspect in the tissue regeneration field in dentistry. Nine different materials have been devised for the representation of the dental pulp and eight for dentin tissue (Table 1). The timespan of the retrieved studies, more than 20 years, shows that this topic has continuously caught the interest of the research community. Well-established techniques that have received multiple publications, such as the perfusion chamber have been customized. New ideas have been further supported by other research groups; the methods were repeated and further validated, as was the case with the entire tooth culture. Furthermore, the field has been enriched with newly emerging ideas from different fields, e.g. 3D printing with bio-inks [47], and by incorporating state of the art with the latest updates in the research field, researchers have managed to include dentistry within these innovative ideas. Another example of this is the "tooth on a chip" which has borrowed the idea from the medical field through the "organ-on-a-chip", finding place also in dentistry [25]. It is essential to mention that some studies sought ways to modify already existing knowledge from two-dimensional studies and bringing insight into the three-dimensional environment [35]. One of the reasons for the high demand in this subject might be the plethora of dental materials aiming to be released in the market with the need for validation and prediction of biohazards before animal testing, or even animal testing with the minimum number of sacrificed animals. The biocompatibility of dental materials and studying the reaction of dental tissues against external stimuli and the similarity to the native tissue is of utmost importance. Improving the resemblance of the in vitro methodology to the natural dentin/pulp complex by combining positive aspects from each of the collected experimental setups seems like a wise option to Replace the use of animal studies, Reduce the number of sacrificed animals and Refine methodology [49].

\section{Literature search and excluded studies}

After the initial search of the four databases, 1196 studies had to be eliminated. Apart from the standard exclusion criteria, such as the type of study - being a review article, clinical trials, in vivo studies or case reports, 
not written in the English language, other significant reasons for exclusion were the following: some studies were attempting to regenerate a three-dimensional analogue of tissues other than the dentin/pulp complex, such as the periodontal bone-ligament, cementum, alveolar bone, periodontium, cartilage, salivary glands etc; other studies were focusing solely on either the dental pulp or dentin but not on the construct of both dentin and pulp; other studies, although matching the keywords for inclusion, they did not offer a detailed report on the manufacturing process of the two tissues and were therefore excluded. As stated initially, the studies that would be included should have a detailed information on the manufacturing of a three-dimensional dentin/pulp construct, therefore after removing the duplicates and the excluded studies, 21 manuscripts were finally included.

\section{Customised cell perfusion chamber}

This system has been developed in a way that many aspects mimic the natural tissue and the pulp responses to external stimuli. In defence of this statement, factors like the introduction of perfusion $0.2-5 \mathrm{ml} / \mathrm{h}$ derive from literature data regarding the pulp flow, which is believed to be $20-82 \mathrm{ml} / \mathrm{min} / 100 \mathrm{~g}$ [10]. The results, as stated by the authors are closer to those retrieved from animal experiments, agar diffusion tests and millipore filter tests and are dissimilar to those found by 2D protocols or direct contact tests when referring to resin modified Glass Ionomer Cements (RMGIC) [41,42]. Furthermore, when considering eugenol containing materials the results agree with animal model studies and studies on human teeth but not with other 2D culture tests such as the agar diffusion and the Millipore test. The simulation to the actual situation may resemble the in vivo tests [38-40] and authors state that the cell perfusion chamber may even be more sensitive than the in vivo tests [12] as the defence mechanisms exerted in the form of immune response are absent in the in vitro situation. The variation of dentin disc is a matter of controversy, as this affects the diffusion of monomers, finally reaching the pulp, the process of sterilisation alters the diffusion potential and the substance absorption by the dental tubules compared to the original tissue [39]. Other decisive factors regarding dentin are the thickness of this tissue [12,38,39], permeability [50], and location [39]. Meaning that thicker dentin discs provide higher protection to the underlying tissue, and number of tubules vary from the centre to the horns of the pulp and from areas proximal to the pulp to more distant locations, thus studies should focus on the consistency with which the methodology is followed [38]. Another important aspect is the timing of observation, as the early time of observation results in higher cytotoxicity values compared to later time points [39]. These studies have shown that the system is quite efficient, as many researchers conclude that there is material-dependent cytotoxicity. This depends on the 
chemical nature of the introduced material [12], some constituents of the materials -as was Dipheniliodonium Chloride for Vitrebond- [38,42], some resin monomers which were more cytotoxic than others- as was bisGMA> UDMA> TEGDMA> HEMA, and also the etching type for bonding agents - where total etch bonding agents were found to be more cytotoxic than self-etch systems [38,39]. For these reasons, this $3 \mathrm{D}$ dentin/pulp complex is under consideration as a strong candidate for replacement of animal models [40-42]. Worthy to mention is the fact that this test has been utilised so extensively, to a point that it has been included in the ISO 7405, for the evaluation of biocompatibility of medical devices used in dentistry [51].

\section{Tooth bud model}

The tooth bud model is a radical method proposed for the regeneration of a biomimetic organ, which will ultimately be able to function in the oral environment as an alternative to synthetic dental implants. All studies stated the importance of Dental epithelial and dental mesenchymal cell communication in the form of crosstalk between the cell lines, as well as the cellular compartmentalization in order to obtain all distinct cell tissues constituting the natural tooth, namely: enamel, dentin, root, pulp, blood vessels, bone and periodontal ligament [18-20]. The developmental stage, the cell seeding density and the substrate of encapsulation were equally important, as cells at cap stage seemed to perform better than cells at bell stage towards the development into teeth, and certain cell-scaffold combinations seemed to perform better for their intended use [18]. These models are promising as they were able to develop normal teeth with complete structures, and they could potentially serve as tools to study organogenesis and the underlying molecular mechanisms as well as the cell interactions at the Dental Epithelial-Dental Mesenchymal interface. Although these are innovative and inspirational attempts, there are still issues to solve, offering space for evolution.

\section{$3 D$ dentin/pulp complex manufactured by tissue engineering}

In this section, the implementation process was diverse, as mentioned earlier. Nonetheless, specific goals were matched for all studies. All studies mentioned the superiority of a 3D dentin/pulp complex over a twodimensional counterpart, forming complete pulp-dentin complexes. This was vastly proven by PCR results showing an increase in dentin specific markers, such as DSPP and others such as RunX2, ALP [35], and angiogenic markers such as VEGF, Angiopoietin-1, and PECAM [35,37]. The stiffness of the scaffold forming the pulp analogue was an important factor as there was a delicate fine-tuning procedure to obtain a pulp-like analogue. Qu et al. attempted this by keeping the concentration of gelatin constant and varying the crosslinking 
density [45], other by varying the concentration of fibrin and fibrinogen [35,47], while this offered control over the differentiation potential of cells into the intended cell populations. Another important characteristic was the utilisation of natural biomaterials for the pulp analogues. Gelatin (a derivative of collagen), collagen, and fibrin or fibrinogen were the major components used for this purpose. The reason for this selection was that fibrin is a biodegradable material with the ability of prevascularization [36], biocompatible with angiogenic by-products [35]. Collagen on the other hand, is a natural constituent of the dental pulp [35]. Dentin was another component of the 3D assemblies which was able to release growth factors sequestered within the matrix that were able to promote cell differentiation into odontoblasts [36] and was also able to host SCAP better than 2D monolayers $[25,35]$ being a source of growth factors, limiting diffusion and acting as a semipermeable membrane for the introduced restorative materials [25]. Isolated points that have to be mentioned here are the real-time monitoring capability of the tooth on a chip device, which offered the potential to track cellular and subcellular responses in an in vivo-like environment [25], the patient-specific capability of 3D printing processes presented by Han et al.[47] offering the potential for personalised tooth - tissue engineering due to the excellent printability of fibrin and DPSCs as a bio-ink, as well as the serum free approach aided by the angiogenetic incorporation of Iloprost, by Seang et al.[37], proposing a dentin/pulp slice as a viable 3D approach for the model to investigate therapeutic approaches towards dentin/pulp regeneration. All in all, these tools are introduced as candidates for risk assessment of restorative materials and monitoring tools for pulp reactions.

\section{Entire tooth culture}

Out of the five analysed categories of this paper, the entire tooth culture model is the most homogeneous in terms of implementation and the one with the maximum resemblance to the native tissue, as it uses the actual tooth in suspension from the cover of the culture dish, reflecting the in vivo situation. In support of this notion, the histological results, after the application of dental materials in cavities are similar to those observed in animal model studies or in vivo studies $([17,44]$. The authors of the four retrieved studies propose that this is a valid model for the study of the early stages of dentinogenesis after inflammation, for the evaluation of responses to pulp capping material application and healing process monitoring $[14,15,17,44]$. So far, this has been evaluated for dental restorative materials such as MTA, calcium hydroxide, Biodentine and has proven that it is worth a spot in the in vitro experimental protocols. Nevertheless, it is not devoid of limitations, which are presented below. 


\section{Tooth slice organ culture}

Similar to the previous category of this paper, the tooth slice organ model was also quite homogeneous in terms of implementation and resemblance to native tissue, since all attributes arose from the same research group. With time, each new publication included more refined information and details, adding valuable knowledge for other groups wishing to reproduce this experimental method. Indeed this method was able to sustain the native tissue morphology -as shown by the histomorphometric analyses- for an adequate time frame -up to 14 dayswhich is a valuable time span for experimentation [30]. This tool is said to be valuable for the injury and repair processes monitoring, as well as cell-matrix interactions and regulation of cell activity of the dentin/pulp tissue $[30,31]$. This is also the only tool that has evolved to the point that it may be used for the study of the effect of indirect external factors (tensile/compressive forces) to the dentin/pulp complex [34]. It is also mentioned as an alternative to in vivo animal cytotoxicity testing for some aspects of the exerted effects by dental materials (Murray), and generally similarities have been observed between the findings of their studies to in vitro and in vivo studies [32].

\section{Limitations}

The perfusion chamber has received multiple modifications through the years and still certain questions and concerns arise inevitably. One of these is the variation of dentin used in this model. This tissue has varying degrees of permeability, which is governed by the location from which the dentin discs have been harvested due to regional differences of the dental tubules. This means that it is so versatile that even within the same location (over the pulp chamber) there are variations between dentin covering the pulp horns and that over the area between the horns, where the former has higher permeability [38]. This could potentially influence the number of stimuli introduced in the system and, ultimately, the effect on the underlying tissue, namely the dental pulp. Another point of interest which could also alter the response compared to the natural tissue, concerning dentin, is the mode of sterilization before incorporation into cell cultures. Authors stated that autoclaving may cause protein denaturation, affecting mainly collagen, which is thermally denatured at 41 degrees Celsius and this may consequently negatively affect the organic components of the tissue [38]. Evidently, this alteration may influence the reactions that would typically occur in the natural tissue. Examples of this could be the hydroxyapatite in dentin that would naturally neutralize acids contained in dental materials under investigation, but this altered form may act differently. Also, ingredients that would normally cross-react with collagen, such as glutaraldehyde, and consequently decrease the cytotoxicity of the adhesive are able to surpass this defensive 
barrier and alter the final response since collagen may be destroyed during preparation procedures [38]. Adding to the issue of defensive mechanisms, the immune reactions taking place in the living tissue are also absent in the in vitro arrangement, namely the inflammation and immune responses of mechanisms of repair [12]. For this reason, the in vitro perfusion chamber is considered to be a more sensitive system than in vivo models, and the results should be regarded with these limitations in mind.

As mentioned earlier, the tooth bud model is an up-and-coming and innovative model, and although progress has been achieved, authors stated that there are still issues to solve. One of these was that although Dental epithelium (DE) and Mesenchyme (DM) were seeded in a distinct manner, they appeared as mixed populations at one week; thus, at certain occasions, no distinct enamel/dentin layer was observed [20]. To address this, the authors suggested that in the future, they should apply sequential photocrosslinking so that the developing tissues will retain compartmentalization. Another suggestion was the addition of dental differentiation growth factors to engage the cellular populations into targeted differentiation directions.

Certain limitations were also stated for the category 3D dentin/pulp complex manufactured by tissue engineering. Han et al. [47] reported that in the future, their 3D printed model should be able to incorporate surrounding tissues (cementum, periodontium) for better representation of the whole tooth. The contraction of the scaffold was another limiting factor when researchers were trying to experiment with the stiffness of the scaffold. The medium and low stiffness scaffolds were presented with contractions, though this was solved by providing a supportive framework made of $\mathrm{b}-\mathrm{TCP}(\mathrm{Qu} 2015)$. On the other hand, this was beneficial as it increased the cellular differentiation potential and cell density providing maximum cell-cell contact [45]. Others stated that since this model was established to represent a cytotoxicity assessment tool, it should incorporate dental restorative materials as a whole, not only constituents of the product. Meaning that studying solely monomers contained within the resin products may neglect other confounding factors that could cause further reactions when reaching the dental pulp analogue [35]. Adding to this notion, França et al.[25] stressed the importance of adding the factor of perfusion as well as the inclusion of immune cells, functional capillaries and innervation, a microbiome and salivary flow [25]. This was not possible at the time of experimentation as it would be difficult to track all the aspects of their device at once, and this could be facilitated by built-in biosensors in further attempts [25].

Regarding the while entire tooth culture model, although it uses the actual freshly extracted dental tissue and it closely simulates the in vivo situation, there are still certain limitations to it. Some of these are the limited duration of in vitro culture - up to four weeks - where the teeth seem to behave similarly to the living teeth 
$[17,44]$. Further drawbacks of this model are the absence of clearance of noxious stimuli due to the absence of blood circulation, oxygen, and nutrient supply $[15,17,44]$. Lastly, as with many in vitro experiments, the inflammation reaction in not represented [44].

Limitations for the category tooth slice organ culture, were stated by the early studies [30]. This was referring to the observation of odontoblast de-polarization and detachment of odontoblasts from predentin, which was caused when mechanical trauma during the tooth sections to obtain the tooth slices.

\section{Conclusions}

To conclude, this paper gathers the evolution of 3D dentin/pulp complexes that are present in literature since 1998. This work aims to stress the increasing efforts through the years to device a tool that may be controllable and handy for the risk assessment of newly introduced biomaterials, minimising the need for animal studies and in vivo tests. Form the findings of these studies, it is evident that innovative ideas still arise, and certain limitations do exist, proving that there is still space for improvement and experimentation. As it is clear, it is not easy to conclude on the superiority of one category over the other as they all come with their strong points and weaknesses. The customised perfusion chamber, the tooth germ model, the different 3D dentin/pulp complexes manufactured by tissue engineering, the entire tooth culture and the tooth slice organ culture are all viable options, as long as their compromises are made clear and the developed protocols are followed closely to avoid pitfalls.

\section{Compliance with ethical standards}

\section{Conflict of interest}

The authors have no conflict of interest to declare.

\section{Funding}

The research work was supported by the Hellenic Foundation for Research and Innovation (HFRI) under the HFRI PhD Fellowship grant (Fellowship Number: 99344).

\section{Ethical approval}

This article does not contain any studies with human participants or animals. 
Informed consent

For this type of study, formal consent is not required.

References

[1] Goldberg M, Hirata A. The Dental Pulp: Composition, Properties and Functions. JSM Dent 2017;5:110.

[2] Mjör IA. Dentin permeability: The basis for understanding pulp reactions and adhesive technology. Braz Dent J 2009;20:3-16. https://doi.org/10.1590/S0103-64402009000100001.

[3] Yu C, Abbott P V. An overview of the dental pulp: Its functions and responses to injury. Aust Dent J 2007;52:S4-6. https://doi.org/10.1111/j.1834-7819.2007.tb00525.x.

[4] Bakopoulou A, Papadopoulos T, Garefis P. Molecular toxicology of substances released from resinbased dental restorative materials. Int J Mol Sci 2009;10:3861-99. https://doi.org/10.3390/ijms10093861.

[5] Hume WR. Restorative Materials and Procedures n.d.:1322-5.

[6] Tyas MJ. A Method for the In Vitro Toxicity Testing of Dental Restorative Materials. J Dent Res 1977;56:1285-90. https://doi.org/10.1177/00220345770560103401.

[7] Meryon SD, Jakeman KJ. An in vitro study of the role of dentine in moderating the cytotoxicity of zinc oxide eugenol cement. Biomaterials 1986;7:459-62. https://doi.org/10.1016/0142-9612(86)90035-9.

[8] Hanks CT, Diehl ML, Craig RG, Makinen P -K, Pashley DH. Characterization of the "in vitro pulp chamber" using the cytotoxicity of phenol. J Oral Pathol Med 1989;18:97-107. https://doi.org/10.1111/j.1600-0714.1989.tb00744.x.

[9] Fitzgerald KA, Malhotra M, Curtin CM, O’Brien FJ, O’Driscoll CM. Life in 3D is never flat: 3D models to optimise drug delivery. J Control Release 2015;215:39-54. https://doi.org/10.1016/j.jconrel.2015.07.020.

[10] Schmalz G, Schuster U, Nuetzel K, Schweikl H. An in vitro pulp chamber with three-dimensional cell cultures. J Endod 1999;25:24-9. https://doi.org/10.1016/S0099-2399(99)80394-X.

[11] Schuster U, Schmalz G, Thonemann B, Mendel N, Metzl C. Cytotoxicity testing with three-dimensional cultures of transfected pulp-derived cells. J Endod 2001;27:259-65. https://doi.org/10.1097/00004770200104000-00004.

[12] Galler K, Hiller KA, Ettl T, Schmalz G. Selective influence of dentin thickness upon cytotoxicity of 
dentin contacting materials. J Endod 2005;31:396-9.

https://doi.org/10.1097/01.don.0000145428.26880.e5.

[13] Van Landuyt KL, Krifka S, Hiller KA, Bolay C, Waha C, Van Meerbeek B, et al. Evaluation of cell responses toward adhesives with different photoinitiating systems. Dent Mater 2015;31:916-27. https://doi.org/10.1016/j.dental.2015.04.016.

[14] Téclès O, Laurent P, Zygouritsas S, Burger AS, Camps J, Dejou J, et al. Activation of human dental pulp progenitor/stem cells in response to odontoblast injury. Arch Oral Biol 2005;50:103-8. https://doi.org/10.1016/j.archoralbio.2004.11.009.

[15] Téclès O, Laurent P, Aubut V, About I. Human tooth culture: A study model for reparative dentinogenesis and direct pulp capping materials biocompatibility. J Biomed Mater Res - Part B Appl Biomater 2008;85:180-7. https://doi.org/10.1002/jbm.b.30933.

[16] Jeanneau C, Laurent P, Rombouts C, Giraud T, About I. Light-cured Tricalcium Silicate Toxicity to the Dental Pulp. J Endod 2017;43:2074-80. https://doi.org/10.1016/j.joen.2017.07.010.

[17] Pedano MS, Li X, Jeanneau C, Ghosh M, Yoshihara K, Van Landuyt K, et al. Survival of human dental pulp cells after 4-week culture in human tooth model. J Dent 2019;86:33-40. https://doi.org/10.1016/j.jdent.2019.05.023.

[18] Nakao K, Morita R, Saji Y, Ishida K, Tomita Y, Ogawa M, et al. The development of a bioengineered organ germ method. Nat Methods 2007;4:227-30. https://doi.org/10.1038/nmeth1012.

[19] Monteiro N, Smith EE, Angstadt S, Zhang W, Khademhosseini A, Yelick PC. Dental cell sheet biomimetic tooth bud model. Biomaterials 2016;106:167-79. https://doi.org/10.1016/j.biomaterials.2016.08.024.

[20] Smith EE, Zhang W, Schiele NR, Khademhosseini A, Kuo CK, Yelick PC. Developing a biomimetic tooth bud model. J Tissue Eng Regen Med 2017;11:3326-36. https://doi.org/10.1002/term.2246.

[21] Wilmer MJ, Ng CP, Lanz HL, Vulto P, Suter-Dick L, Masereeuw R. Kidney-on-a-Chip Technology for Drug-Induced Nephrotoxicity Screening. Trends Biotechnol 2016;34:156-70. https://doi.org/10.1016/j.tibtech.2015.11.001.

[22] Wevers NR, Kasi DG, Gray T, Wilschut KJ, Smith B, Vught R, et al. A perfused human blood-brain barrier on-a-chip for high-throughput assessment of barrier function and antibody transport. Fluids Barriers CNS 2018;15:1-12. https://doi.org/10.1186/s12987-018-0108-3.

[23] Bovard D, Sandoz A, Luettich K, Frentzel S, Iskandar A, Marescotti D, et al. A lung/liver-on-a-chip 
platform for acute and chronic toxicity studies. Lab Chip 2018;18:3814-29.

https://doi.org/10.1039/c81c01029c.

[24] Deng J, Wei W, Chen Z, Lin B, Zhao W, Luo Y, et al. Engineered liver-on-a-chip platform to mimic liver functions and its biomedical applications: A review. Micromachines 2019;10:1-26. https://doi.org/10.3390/mi10100676.

[25] França CM, Tahayeri A, Rodrigues NS, Ferdosian S, Puppin-Rontani R, Ferracane JL, et al. The tooth on-a-chip: a microphysiologic model system mimicking the pulp-dentin interface and its interaction with biomaterials. BioRxiv 2019:748053. https://doi.org/10.1101/748053.

[26] Elliott N, Yuan F. A review of Three-Dimensional In Vitro Tissue Models for drus discovery and transport studies. J Pharm Sci 2011;100:59-74. https://doi.org/10.1002/jps.

[27] Hoarau-Véchot J, Rafii A, Touboul C, Pasquier J. Halfway between 2D and animal models: Are 3D cultures the ideal tool to study cancer-microenvironment interactions? Int J Mol Sci 2018;19. https://doi.org/10.3390/ijms19010181.

[28] Moher D, Liberati A, Tetzlaff J, Altman DG, Altman D, Antes G, et al. Preferred reporting items for systematic reviews and meta-analyses: The PRISMA statement. PLoS Med 2009;6. https://doi.org/10.1371/journal.pmed.1000097.

[29] Schmalz G, Gröppel F, Hiller KA, Galler KM. Trodimenzionalne kulture ljudskih stanica uzgojene radi testiranja citotoksičnosti stomatoloških materijala. Acta Stomatol Croat 2014;48:99-108. https://doi.org/10.15644/asc48/2.99.

[30] Sloan AJ, Shelton RM, Hann AC, Moxham BJ, Smith AJ. An in vitro approach for the study of dentinogenesis by organ culture of the dentine-pulp complex from rat incisor teeth. Arch Oral Biol 1998;43:421-30. https://doi.org/10.1016/S0003-9969(98)00029-6.

[31] Sloan AJ, Smith AJ. Stimulation of the dentine-pulp complex of rat incisor teeth by transforming growth factor- $\beta$ isoforms 1-3 in vitro. Arch Oral Biol 1999;44:149-56. https://doi.org/10.1016/S00039969(98)00106-X.

[32] Dobie K, Smith G, Sloan AJ, Smith AJ. Effects of alginate hydrogels and TGF- $\beta 1$ on human dental pulp repair in vitro. Connect Tissue Res 2002;43:387-90. https://doi.org/10.1080/03008200290000574.

[33] Murray PE, Windsor LJ, Smyth TW, Hafez AA, Cox CF. Analysis of pulpal reactions to restorative procedures, materials, pulp capping, and future therapies. Crit Rev Oral Biol Med 2002;13:509-20. https://doi.org/10.1177/154411130201300607. 
[34] Dhopatkar AA, Sloan AJ, Rock WP, Cooper PR, Smith AJ. British Orthodontic Society, Chapman Prize Winner 2003: Anovel in vitro culture model to investigate the reaction of the dentine-pulp complex to orthodontic force. J Orthod 2005;32:122-32. https://doi.org/10.1179/146531205225020979.

[35] Hadjichristou C, Papachristou E, Bonovolias I, Bakopoulou A. Dentin / Pulp tissue analogue as advanced biocompatibility evaluation tool of dental restorative materials. Dent Mater 2019:1-20. https://doi.org/10.1016/j.dental.2019.11.013.

[36] Aksel H, Huang GTJ. Combined Effects of Vascular Endothelial Growth Factor and Bone Morphogenetic Protein 2 on Odonto/Osteogenic Differentiation of Human Dental Pulp Stem Cells In Vitro. J Endod 2017;43:930-5. https://doi.org/10.1016/j.joen.2017.01.036.

[37] Seang S, Pavasant P, Limjeerajarus CN. Iloprost Induces Dental Pulp Angiogenesis in a Growth Factorfree 3-Dimensional Organ Culture System. J Endod 2018;44:759-764.e2. https://doi.org/10.1016/j.joen.2018.02.001.

[38] Jiang RD, Lin H, Zheng G, Zhang XM, Du Q, Yang M. In vitro dentin barrier cytotoxicity testing of some dental restorative materials. J Dent 2017;58:28-33. https://doi.org/10.1016/j.jdent.2017.01.003.

[39] Engn A, Yaln M, Lker HE, Ztrk B, Hakk SS. Cytotoxicity evaluation of dentin bonding agents by dentin barrier test on 3-dimensional pulp cells. Oral Surgery, Oral Med Oral Pathol Oral Radiol Endodontology 2011;112:83-8. https://doi.org/10.1016/j.tripleo.2011.02.023.

[40] Ulker HE, Sengun A. Cytotoxicity Evaluation of Self Adhesive Composite Resin Cements by Dentin Barrier Test on 3D Pulp Cellss. Eur J Dent 2009;03:120-6. https://doi.org/10.1055/s-0039-1697418.

[41] Schmalz G, Schuster U, Koch A, Schweikl H. Cytotoxicity of low pH dentin-bonding agents in a dentin barrier test in vitro. J Endod 2002;28:188-92. https://doi.org/10.1097/00004770-200203000-00011.

[42] Schuster U, Schmalz G, Thonemann B, Mendel N MC. Cytotoxicity testing with three-dimensional cultures of transfected pulp-derived cells. J Endod 2001;27:259-65. https://doi.org/10.1097/00004770200104000-00004.

[43] da Silva JMF, Rodrigues JR, Camargo CHR, Fernandes VVB, Hiller KA, Schweikl H, et al. Effectiveness and biological compatibility of different generations of dentin adhesives. Clin Oral Investig 2014;18:607-13. https://doi.org/10.1007/s00784-013-1000-9.

[44] Laurent P, Camps J, About I. Biodentine TM induces TGF- $\beta 1$ release from human pulp cells and early dental pulp mineralization. Int Endod J 2012;45:439-48. https://doi.org/10.1111/j.13652591.2011.01995.x. 
[45] Qu T, Jing J, Ren Y, Ma C, Feng JQ, Yu Q, et al. Complete pulpodentin complex regeneration by modulating the stiffness of biomimetic matrix. Acta Biomater 2015;16:60-70. https://doi.org/10.1016/j.actbio.2015.01.029.

[46] Murray PE, Lumley PJ, Ross HF, Smith AJ. Tooth slice organ culture for cytotoxicity assessment of dental materials. Biomaterials 2000;21:1711-21. https://doi.org/10.1016/S0142-9612(00)00056-9.

[47] Han J, Kim DS, Jang H, Kim HR, Kang HW. Bioprinting of three-dimensional dentin-pulp complex with local differentiation of human dental pulp stem cells. J Tissue Eng 2019;10. https://doi.org/10.1177/2041731419845849.

[48] Schuster U, Schmalz G, Thonemann B, Mendel N MC. Cytotoxicity testing with three-dimensional cultures of transfected pulp-derived cells. J Endod 2001;27:259-65. https://doi.org/10.1097/00004770$200104000-00004$.

[49] Bhattacharya S, Zhang Q, Carmichael PL, Boekelheide K, Andersen ME. Toxicity testing in the 21st century: Defining new risk assessment approaches based on perturbation of intracellular toxicity pathways. PLoS One 2011;6. https://doi.org/10.1371/journal.pone.0020887.

[50] Schmalz G, Hiller KA, Nunez LJ, Stoll J, Weis K. Permeability characteristics of bovine and human dentin under different pretreatment conditions. J Endod 2001;27:23-30. https://doi.org/10.1097/00004770-200101000-00007.

[51] ISO 7405: International Organization for Standardization, ISO 7405:2018 Dentistry — Evaluation of Biocompatibility of Medical Devices Used in Dentistry, ISO, Geneva 2018http://www.iso.org/iso/store.htm. ISO 7405:2018 Dentistry— Evaluation of Biocompatibility ofMedical Devices Used in Dentistry, ISO,. ISO, Geneva 2018:7. http://www.iso.org/iso/store.htm. 